Graziela de Araujo Costa Zanatta

\title{
Avaliação do prognóstico com a utilização de dois escores de mortalidade em terapia intensiva pediátrica de nível de atendimento terciário
}

Tese apresentada à Faculdade de Medicina da Universidade de São Paulo para obtenção do título de Doutor em Ciências

Programa de Pediatria

Orientador: Prof. Dr. Artur Figueiredo Delgado 
Dados Internacionais de Catalogação na Publicação (CIP)

Preparada pela Biblioteca da

Faculdade de Medicina da Universidade de São Paulo

Creprodução autorizada pelo autor

\section{Zanatta, Graziela de Araujo Costa}

Avaliação do prognóstico com a utilização de dois escores de mortalidade em terapia intensiva pediátrica de nível de atendimento terciário / Graziela de Araujo Costa Zanatta. -- São Paulo, 2016.

Tese(doutorado)--Faculdade de Medicina da Universidade de São Paulo.

Programa de Pediatria.

Orientador: Artur Figueiredo Delgado.

Descritores: 1.Unidades de terapia intensiva pediátrica 2.Prognóstico 3.Mortalidade 4.Controle de qualidade 5.Índice de gravidade de doença 6. Qualidade da assistência à saúde 7.Atenção terciária à saúde

USP/FM/DBD-036/16 
"Ter desafios é o que faz a vida interessante e superá-los é o que faz a vida ter sentido."

Toshua I. Marine

"No que diz respeito ao empenho, ao compromisso, ao esforço, à dedicação, não existe meio termo. Ou você faz uma coisa bem feita, ou não faz." 


\section{DEDICATÓRIA}

Aos meus pais, Edna e Jorge, a quem tanto estimo e que sempre estiveram ao meu lado, que tanto se dedicaram à minha educação, mesmo nos momentos mais difíceis, que estão sempre dispostos a me ajudar e torcendo por mim.

Aos meus avós, Emília e Luiz, que Graças a Deus ainda tenho a oportunidade de conviver e que sempre me deram carinho e atenção.

Aos meus irmãos, Jorge e Paula, aos meus tios, tias, primos e primas, que sempre torceram por mim e que por muitas vezes cuidaram dos meus filhos para que eu pudesse me dedicar aos plantões e ao doutorado.

À minha tia, Tata, por me escutar nos momentos de angústia e pelos conselhos espirituais.

Aos meus queridos afilhados, Júlia, Lucas, Manuela e Pedro, que deram um sentido especial à minha vida.

Ao meu marido, Rodrigo, que esteve ao meu lado em todos os momentos, que compreende meus defeitos, cuida de mim e soube compreender cada ausência minha.

Ao meu querido filho, Felipe, que foi gerado durante a elaboração do meu mestrado, me ensinou o amor incondicional, e me inspira a cada dia ser uma mãe melhor.

À minha querida filha, Maria Eduarda, que nasceu durante a elaboração desta tese de doutorado, que veio completar nossa família e me ensinou que o amor não se divide, se multiplica. 


\section{AGRADECIMENTOS}

Ao grande Prof. Dr. Artur Figueiredo Delgado, meu orientador, a quem tenho enorme admiração e carinho. Agradeço os ensinamentos, a paciência e dedicação, indispensáveis para a elaboração dessa tese e para meu crescimento profissional.

Ao meu querido Prof. Dr. Eduardo Juan Troster, que continua presente em minha trajetória pessoal e profissional, responsável por meu interesse pela pesquisa. Exemplo de ética, integridade e caráter.

Ao Prof. Dr. José Roberto Fioretto, pessoa e profissional admirável, responsável pela minha paixão pela pediatria e terapia intensiva pediátrica desde a graduação, que esteve presente em todos os momentos da minha trajetória no mestrado e doutorado.

Ao Prof. Dr. Vicente Odone Filho, a quem muito estimo pelo caráter e dedicação aos pacientes e à instituição, pela oportunidade de trabalhar na UTI do ITACI.

Ao Dr. Alexandre Ferraro, pela experiência compartilhada em epidemiologia, pela paciência e disponibilidade com meus pedidos de ajuda e pela orientação nas análises estatísticas.

Aos meus colegas de trabalho da UTI pediátrica do Hospital Sírio Libanês, em especial a Daniela Carla de Souza, com quem tive o prazer de compartilhar algumas disciplinas da pós-graduação e que dividiu comigo as angústias do doutorado.

Às minhas colegas de trabalho e acima de tudo amigas, Alessandra Azambuja, Ana Lucia Cornacchioni e Katia Oliveira pela ajuda e torcida e por estarem sempre ao meu lado em todos os momentos, inclusive nos mais difíceis. 
À equipe médica da UTI do ITACI do Instituto da Criança - HCFMUSP, que tenho grande admiração e orgulho e que tanto se empenham nesse nosso desafio de cuidar dos nossos pacientes oncológicos.

À equipe de enfermagem e fisioterapia da UTI do ITACI do Instituto da Criança - HCFMUSP, que diariamente se dedica aos pacientes internados.

À Mariza Kazue Umetsu, por todo o apoio, colaboração e paciência no levantamento bibliográfico, não somente desta tese, mas sempre que precisei, com atenção e carinho. 
Esta tese está de acordo com as seguintes normas, em vigor no momento desta publicação:

Referências: adaptado de International Committee of Medical Journals Editors (Vancouver).

Universidade de São Paulo. Faculdade de Medicina. Serviço de Biblioteca e Documentação. Guia de apresentação de dissertações, teses e monografias.

Elaborado por Anneliese Carneiro da Cunha, Maria Julia de A. L. Freddi, Maria F. Crestana, Marinalva de Souza Aragão, Suely Campos Cardoso, Valéria Vilhena. $3^{a}$ ed. São Paulo: Divisão de Biblioteca e Documentações; 2011.

Abreviatura dos títulos dos periódicos de acordo com List of Journals Indexed in Index Medicus. 


\section{SUMÁRIO}

Lista de abreviaturas e siglas

Lista de tabelas

Resumo

Abstract

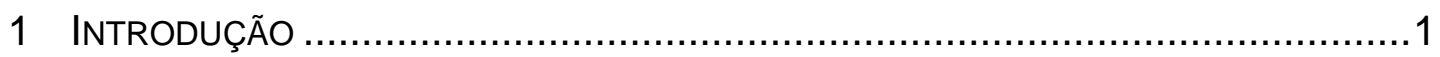

1.1 Histórico dos Escores Preditivos nas Unidades de Terapia

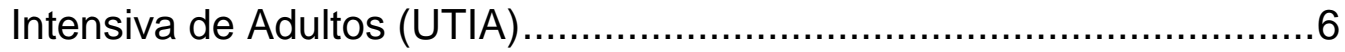

1.2 Escores Preditivos de Mortalidade em Pediatria ...................................

1.3 Avaliação de um Sistema de Escore ................................................14

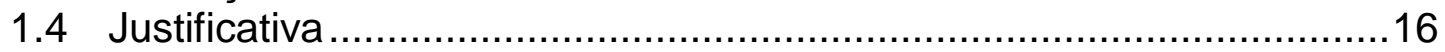

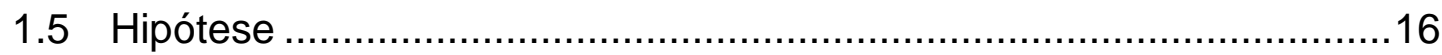

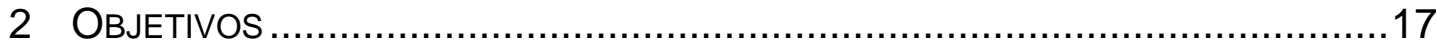

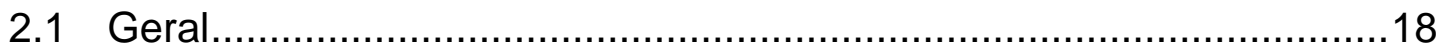

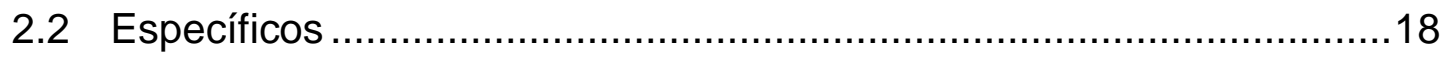

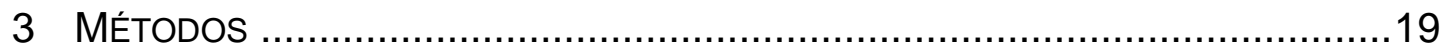

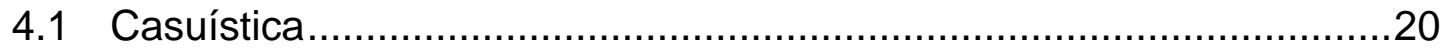

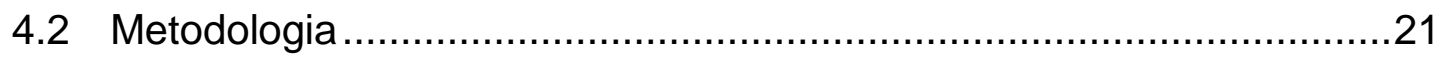

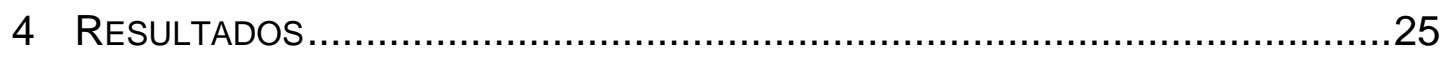

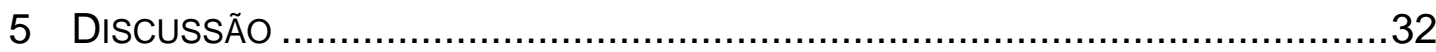

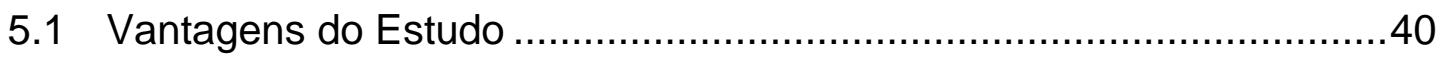

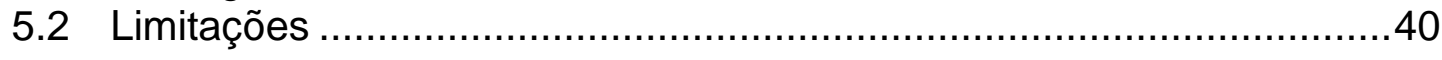

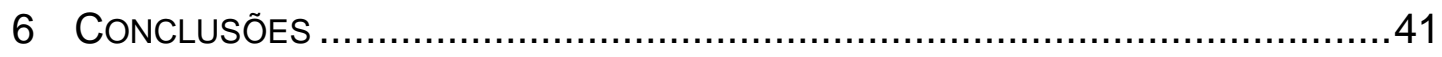

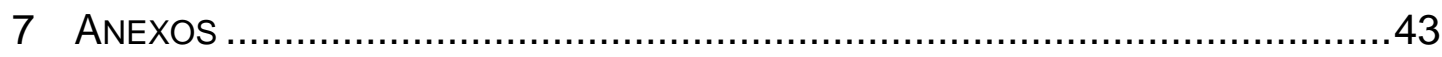

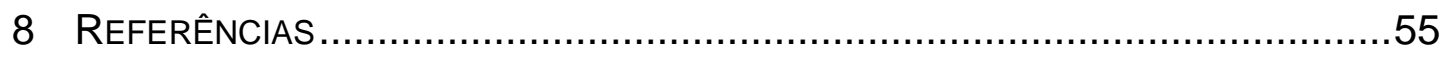

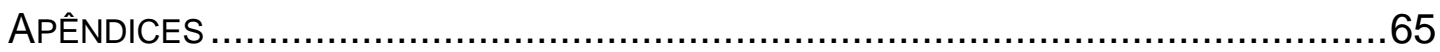




\section{LISTA DE ABREVIATURAS E SIGLAS}

$\begin{array}{ll}\text { APACHE } & \text { - Acute Physiology and Chronic Health Evaluation } \\ \text { APS } & \text { - Acute Physiology Score } \\ \text { CAPPesq } & \text { - Comissão de Ética para Análise de Projetos de Pesquisa } \\ \text { DCC } & \text { - Doença crônica complexa } \\ \text { ECG } & \text { - Escala de Coma de Glasgow } \\ \text { PIM } & \text { - Pediatric Index of Mortality } \\ \text { PRISM } & \text { - Pediatric Risk of Mortality } \\ \text { PSI } & \text { - Physiologic Stability Index } \\ \text { ROC } & - \text { Receiver Operating Characteristics } \\ \text { RTS } & - \text { Escore de Trauma Revisado } \\ \text { SAPS } & - \text { Simplified Acute Physiology Score } \\ \text { SMR } & - \text { Standardized Mortality Ratio } \\ \text { UTI } & - \text { Unidade de terapia intensiva } \\ \text { UTIA } & - \text { Unidade de terapia intensiva de adultos } \\ \text { UTIP } & - \text { Unidade de terapia intensiva pediátrica }\end{array}$




\section{LISTA DE TABELAS}

Tabela 1 - Características dos pacientes do estudo .................................27

Tabela 2 - Comparação do PRISM e PIM2 entre pacientes que foram a óbito e sobreviventes

Tabela 3 - Standardized Mortality Ratio (SMR) dos escores PRISM e PIM2 para subgrupos de idade e tipo de paciente (cirúrgico ou clínico)

Tabela 4 - Calibração dos escores PRISM e PIM2 para os subgrupos idade, tempo de internação na UTIP e motivo principal da admissão por meio do teste de HosmerLemeshow

Tabela 5 - Comparação da discriminação do PRISM e PIM2 para os subgrupos idade, tempo de internação na UTIP e motivo principal da admissão por meio da área sob a curva ROC

Tabela 6 - Sensibilidade e Especificidade das diversas pontuações do PRISM 


\section{RESUMO}

Zanatta GAC. Avaliação do prognóstico com a utilização de dois escores de mortalidade em terapia intensiva pediátrica de nível de atendimento terciário [tese]. São Paulo: Faculdade de Medicina, Universidade de São Paulo; 2016.

A redução da mortalidade é um objetivo fundamental das unidades de terapia intensiva pediátrica (UTIP). O estágio de gravidade da doença reflete a magnitude das comorbidades e distúrbios fisiológicos no momento da internação e pode ser avaliada pelos escores prognósticos de mortalidade. Os dois principais escores utilizados na UTIP são o Pediatric Risk of Mortality (PRISM) e o Pediatric Index of Mortality (PIM). O PRISM utiliza os piores valores de variáveis fisiológicas e laboratoriais nas primeiras 24 horas de internação enquanto o PIM2 utiliza dados da primeira hora de internação na UTIP e apenas uma gasometria arterial. Não há consenso na literatura, entre PRISM e PIM2, quanto à utilidade e padronização na admissão na terapia intensiva para as crianças e adolescentes, principalmente em uma UTI de nível de atendimento terciário. O objetivo do estudo foi estabelecer o escore de melhor performance na avaliação do prognóstico de mortalidade que seja facilmente aplicável na rotina da UTIP, para ser utilizado de forma padronizada e contínua. Foi realizado um estudo retrospectivo onde foram revisados os escores PRISM e PIM2 de 359 pacientes internados na unidade de terapia intensiva pediátrica do Instituto da Criança do Hospital das Clínicas da Faculdade de Medicina da USP, considerada uma unidade de atendimento de nível terciário. A mortalidade foi de $15 \%$, o principal tipo de admissão foi clinico (78\%) sendo a principal causa de internação a disfunção respiratória $(37,3 \%)$. Os escores dos pacientes que foram a óbito mostraram-se maiores do que o dos sobreviventes. Para o PRISM foi 15 versus $7(p=0,0001)$ e para o PIM2, 11 versus $5(p=0,0002)$, respectivamente. Para a amostra geral, o Standardized Mortality Ratio 
(SMR) subestimou a mortalidade tanto para o PIM2 quanto para o PRISM $[1,15(0,84-1,46)$ e $1,67(1,23-2,11)$, respectivamente]. O teste de HosmerLemeshow mostrou calibração adequada para ambos os escores $\left[x^{2}=12,96\right.$ $(p=0,11)$ para o PRISM e $x^{2}=13,7(p=0,09)$ para o PIM2]. $A$ discriminação, realizada por meio da área sob a curva $\mathrm{ROC}$, foi mais adequada para o PRISM do que para o PIM2 [0,76 (IC 95\% 0,69-0,83) e $0,65$ (IC 95\% 0,57 - 0,72), respectivamente, $p=0,002]$. No presente estudo, a melhor sensibilidade e especificidade para o risco de óbito do PRISM foi um escore entre 13 e 14, mostrando que, com o avanço tecnológico, o paciente precisa ter um escore mais elevado, ou seja, maior gravidade clínica do que a população original, para um maior risco de mortalidade. Os escores de gravidade podem ter seus resultados modificados em consequência: do sistema de saúde (público ou privado), da infraestrutura da UTIP (número de leitos, recursos humanos, parque tecnológico) e indicação da internação. A escolha de um escore de gravidade depende das características individuais da UTIP, como o tempo de espera na emergência, presença de doença crônica complexa (por exemplo, pacientes oncológicos) e como é realizado o transporte para a UTIP. Idealmente, estudos multicêntricos têm maior significância estatística. No entanto, estudos com populações maiores e mais homogêneas, especialmente nos países em desenvolvimento, são difíceis de serem realizados.

Descritores: Unidades de terapia intensiva pediátrica. Prognóstico. Mortalidade. Controle de qualidade. Índice de gravidade de doença. Qualidade da assistência à saúde. Atenção terciária à saúde. 


\begin{abstract}
Zanatta GAC. Performance of two prognostic scores systems in a tertiary pediatric intensive care unit in a developing country [thesis]. São Paulo: "Faculdade de Medicina, Universidade de São Paulo"; 2016.
\end{abstract}

The decrease in mortality is a fundamental goal of the pediatric intensive care unit (PICU). The disease severity reflects the magnitude of comorbidities and physiological disorders on admission and can be assessed by the mortality prognostic scores. The two main scores used in the PICU are the Pediatric Risk of Mortality (PRISM) and Pediatric Index of Mortality (PIM). PRISM uses the worst values of physiological and laboratory variables in the first 24 hours of hospitalization while PIM2 uses data from the first hour after admission to the PICU and only one arterial blood gas. There is no consensus in the literature, between PRISM and PIM2, about usefulness and standardization on admission to intensive care for children and adolescents, especially in a tertiary care level ICU. The aim of the study was to establish the score of best performance in assessing the mortality prognosis that is easily applicable in routine PICU, to be used in a standardized and continuously manner. A retrospective study was conducted and PRISM and PIM2 scores of 359 patients were reviewed. All of them were admitted to the pediatric intensive care unit of the Instituto da Criança do Hospital das Clínicas da Faculdade de Medicina da Universidade de São Paulo, considered a tertiary care unit. Mortality was 15\%, the main type of admission was clinical (78\%) being the main cause of hospitalization, respiratory dysfunction (37.3\%). The scores of the patients who died were higher than that of survivors. For PRISM was 15 versus $7(p=0.0001)$ and the PIM2, 11 versus $5(\mathrm{p}=0.0002)$, respectively. For the overall sample, the Standardized Mortality Ratio (SMR) underestimated mortality for both PIM2 and PRISM [1.15 (0.84 to 1.46$)$ and 1.67 (1.23 to 2.11$)$, respectively]. The 
Hosmer-Lemeshow test showed adequate calibration for both scores $\left[\mathrm{x}^{2}=\right.$ $12.96(p=0.11)$ for the PRISM and $x^{2}=13.7(p=0.09)$ for PIM2]. The discrimination performed by the area under the ROC curve was more than adequate for the PRISM than for PIM2 [0.76 $(95 \% \mathrm{Cl} 0.69-0.83)$ and 0.65 $(95 \% \mathrm{Cl} 0,57-0.72)$, respectively, $p=0.002]$. In this study, the greatest sensitivity and specificity for this risk would be a PRISM score between 13 and 14, showing that with technological advances, the patient needs a score that is higher and indicates greater clinical severity compared with the original population to reflect an increased risk of mortality. The severity scores may have their results changed as a result: the health system (public or private), the infrastructure PICU (number of beds, human resources, technology park) and statement of admission. The choice of a severity score depends on the individual characteristics of the PICU, as the waiting time in the emergency, the presence of complex chronic disease (for example, oncological patients) and how the transport to the PICU is carried out. Ideally, multicenter studies have greater statistical significance. However, studies with larger and more homogeneous populations, especially in developing countries, are difficult to perform.

Descritors: Intensive care units. Pediatric. Prognosis. Mortality. Quality control. Severity of illness index. Quality of health care. Tertiary healthcare. 
1 INTRODUÇÃO 
A redução da mortalidade é um objetivo fundamental das unidades de terapia intensiva pediátrica (UTIP) (Bekhit et al., 2014). Com o avanço tecnológico nas unidades de terapia intensiva (UTIs), houve aumento na complexidade dos cuidados prestados aos pacientes, tornando-as aptas ao atendimento de casos graves e de elevado custo. Porém, a tecnologia disponível não necessariamente melhorou a qualidade de atendimento, prolongando, muitas vezes, a dor, o sofrimento e o processo de morte (Batista et al., 2009). Com isto, tornou-se necessário caracterizar o estágio de gravidade da doença, que reflete a magnitude das comorbidades e distúrbios fisiológicos no momento da internação (Pollack et al., 1988).

Todo o histórico dos escores de mortalidade encontra-se centrado em métodos fisiológicos, subjetivos e objetivos aplicados aos pacientes internados em uma unidade de cuidados intensivos (Garcia e Piva, 2007). A subjetividade dos profissionais de saúde serviu como os primórdios de escores prognósticos sendo que a simples observação servia muitas vezes para definir a evolução dos pacientes e a conduta a ser adotada. Porém, viu-se que isso não era o bastante, pois a precisão de um médico em estimar o risco de mortalidade para os pacientes internados na UTI é muito subjetiva (Bekhit et al., 2014).

Os resultados dos estudos que investigam o perfil demográfico, mortalidade, morbidade e permanência média nas UTIs variam em função 
das características particulares de diversos países e mesmo entre serviços de saúde diferentes no mesmo país. Devido a essas divergências, há necessidade de melhorar a compreensão dos resultados de cuidados intensivos para permitir a alocação mais adequada de recursos humanos, tecnológicos e financeiros. Por isso, estudos têm sido realizados para avaliar diferentes métodos para predizer a gravidade e o risco de mortalidade nas UTIs (Netto et al., 2014).

Os sistemas de escore são utilizados, na prática médica, para medir os déficits fisiológicos a fim de proporcionar pontos de referência imediatamente reconhecíveis por outros observadores, a partir dos quais a resposta ao tratamento pode ser imediata (Waters e Nightingale, 1990). Eles são usados para indicar a gravidade (Wheeler, 2009) e para avaliar o risco de mortalidade nas UTls sendo uma parte essencial da prestação de cuidados intensivos. Eles permitem comparações entre unidades e dentro da própria unidade com o tempo e também fornecem informações úteis para comparar a gravidade da doença dos pacientes em ensaios clínicos (Sankar et al., 2014).

As crianças criticamente enfermas, assim como os adultos, apresentam distúrbios da homeostase corpórea, que podem ser avaliados por meio da quantificação das variáveis fisiológicas. Os sistemas de escores são um meio de quantificar esses distúrbios, avaliando a condição clínica do paciente na admissão ou durante a internação. Eles foram desenvolvidos em resposta a crescente ênfase na avaliação e monitorização dos serviços de saúde.

Embora o conceito de qualidade em saúde não seja novo, nos últimos 20 anos sua aplicabilidade vem se tornando cada vez mais frequente com 
enfoque na excelência do atendimento e na segurança do paciente durante o tratamento, principalmente em terapia intensiva, devido ao impacto significante no prognóstico (morbidade, mortalidade, prognóstico funcional) e nos custos.

Os escores prognósticos de mortalidade são úteis para avaliar a qualidade do atendimento, comparar diferentes serviços, dimensionar os profissionais de acordo com o grau de complexidade, determinar o prognóstico e estimar o risco de mortalidade (Martha et al., 2005).

A utilização de um escore prático e objetivo, que apresente critérios clínicos e/ou laboratoriais que não retardem o tratamento dos pacientes é fator de impacto na qualidade de atendimento dos pacientes gravemente doentes.

O escore ideal deveria ser de fácil aplicação, não exigir grande experiência do observador, ser facilmente reprodutível, ter baixo custo, ser pouco invasivo e ser preciso. Outro ponto importante é o escore avaliar um período de medição que seja suficiente para incluir todas as medidas adequadas que sejam importantes para avaliar o prognóstico, mas curto o suficiente para minimizar os efeitos da terapia sobre os valores de variáveis para representar a "verdadeira" gravidade na admissão da UTI e que não impõe viés institucional. Para algumas variáveis, como frequência cardíaca e pressão arterial, as medidas são tão frequentes que curtos períodos de avaliação incluem seus valores. Entretanto, algumas variáveis laboratoriais que tem comprovada informação prognóstica, são medidas infrequentemente e necessitariam de um período maior para serem utilizadas. Ao mesmo tempo, porém, o período de avaliação deve ser tão curto quanto possível para 
minimizar os efeitos da terapia sobre a estimativa inicial de gravidade de doença, especialmente se os efeitos do método de gravidade incluem a avaliação da qualidade dos cuidados (Pollack et al., 2013).

É importante que, antes da utilização de um escore, ele seja validado na UTIP na qual pretende se usado uma vez que a população na qual ele será aplicado difere daquela em que o escore foi criado e validado.

O uso dos escores de gravidade são obrigatórios nas UTIs brasileiras de acordo com a Sessão IX (Avaliação), artigo 48 da resolução ํo 7, de 24 de fevereiro de 2010, do Ministério da Saúde, Agência Nacional de Vigilância Sanitária, publicada no Diário Oficial da União:

"Devem ser monitorados e mantidos registros de avaliações do desempenho e do padrão de funcionamento global da UTI, assim como de eventos que possam indicar necessidade de melhoria da qualidade da assistência, com o objetivo de estabelecer medidas de controle ou redução dos mesmos.

$\S 1^{\circ}$ Deve ser calculado o Índice de Gravidade/Índice Prognóstico dos pacientes internados na UTI por meio de um Sistema de Classificação de Severidade de Doença recomendado por literatura científica especializada.

$\S 2^{\circ}$ O Responsável Técnico da UTI deve correlacionar a mortalidade geral de sua unidade com a mortalidade geral esperada, de acordo com o Índice de gravidade utilizado. 


\subsection{Histórico dos Escores Preditivos nas Unidades de Terapia Intensiva de Adultos (UTIA)}

Em 1974, Teasdale e Jennett introduziram a Escala de Coma de Glasgow (ECG), que atualmente é utilizada internacionalmente para descrever alterações do nível de consciência, havendo inclusive uma modificação para crianças no componente de resposta verbal, proposta em 1989 e utilizada até hoje. A ECG é parte integral de alguns escores prognósticos como Escore de Trauma Revisado (RTS), Simplified Acute Physiology Score (SAPS) e Acute Physiology and Chronic Health Evaluation II (APACHE II) (Knaus et al., 1985; Waters e Nightingale, 1990).

Nos últimos 50 anos houve mudança de enfoque na Terapia Intensiva, passando a ênfase do diagnóstico para a terapêutica. Sendo esse fato associado ao investimento em tecnologia complexa e de alto custo, há necessidade de obter evidência das indicações e benefícios dos diversos tipos de tratamento na UTI. Uma das melhores formas de obter essas evidências é por meio da estimativa do prognóstico analisando os escores de mortalidade que devem ser válidos para ampla gama de diagnósticos, fácil de serem utilizados e baseados em dados disponíveis na maioria dos hospitais (Knaus et al., 1985).

Nas UTIA os escores preditivos de mortalidade são utilizados desde a década de 80. O Acute Physiology and Chronic Health Evaluation (APACHE) continua sendo o escore mais utilizado para estimar gravidade e prognóstico (Wheeler, 2009). O APACHE I foi criado em 1981, por Knaus et al. com o objetivo de desenvolver um sistema baseado em dados fisiológicos que fossem capaz de estratificar a gravidade da doença e permitir a comparação 
multicêntrica e internacional dos dados obtidos. A pontuação é obtida por meio da soma de três componentes: o escore fisiológico agudo [Acute Physiology Score (APS)], a idade e a presença de doença crônica. A natureza da admissão (médica, cirúrgica, eletiva ou de emergência) também é levada em consideração no cálculo do escore. O APS é composto de 34 variáveis, cada uma com pontuação de zero a quatro, sendo o resultado final obtido por meio da soma dos piores valores das primeiras 24 horas de admissão na UTI, porém, não é obrigatória a utilização de todas as variáveis, caso faltem dados presumidos como normal. A presença ou não de doença crônica é baseada em quatro letras, sendo (A) ausência de doença crônica (saudável) e (D) insuficiência crônica grave de algum órgão. Quando maior o escore, maior a gravidade do paciente e maior o risco de óbito (Waters e Nightingale, 1990; Knaus et al., 1985).

Como o APACHE I é difícil de ser aplicado na prática, devido à complexidade e grande número de variáveis, foram desenvolvidos os: SAPS, em 1984 por Le Gall et al., e o APACHE II, em 1985 por Knaus et al. As variáveis mensuráveis foram reduzidas para 13 e 12, respectivamente. Ambos utilizam a idade para obtenção da pontuação do escore.

O SAPS foi validado em oito UTIs na França, utilizando os piores valores das primeiras 24 horas de admissão (Le Gall et al., 1983; Waters e Nightingale, 1990). Em 1993 este escore foi atualizado, sendo criado e validado o SAPS II (Le Gall et al., 1993), realizado em 137 UTIA de 12 países, onde foram randomizados 13.152 pacientes (foram excluídos pacientes menores de 18 anos e os que foram internados por queimaduras, 
cirurgia coronariana ou cardíaca); utiliza 17 variáveis: 12 fisiológicas, idade, tipo de admissão e três tipos de doença de base, demonstrando uma melhor correlação entre seu valor e a mortalidade nas UTIs (Anexo A).

O APACHE II, criado a partir do APACHE I, também utiliza os princípios fisiológicos para estratificar os pacientes criticamente enfermos quanto ao risco de óbito e utilizou as sugestões de Gustafson et al. (1981) para construção de escores de gravidade e o princípio da homeostase para a atualização do mesmo. Por meio de análise estatística, reduziu de 34 para 12 variáveis, eliminando alguns dados potencialmente redundantes e outros poucos utilizados na prática diária, como osmolaridade sanguínea e testes cutâneos para anergias. Tornou-se obrigatório o uso de todas as variáveis para o cálculo do escore e devem ser utilizados os piores dados das primeiras 24 horas de admissão na UTI, sendo 71 sua pontuação máxima (Anexo B). Como a idade e a presença de doença crônica refletem diminuição das reservas fisiológicas, ambas foram incorporadas ao escore. Além disso, a partir das análises estatísticas foi dada maior importância à classe (D) de doenças crônicas (insuficiência crônica grave de algum órgão ou imunodeficiência) e aos pacientes não cirúrgicos ou que são submetidos à cirurgias de emergência, pois esses grupos apresentam maior risco de óbito. A validação do escore foi obtida por meio de sua utilização em 13 hospitais, comparando sua pontuação com a mortalidade ocorrida. A cada cinco pontos de aumento no escore, há aumento significativo da probabilidade de óbito hospitalar embora esse risco esteja intimamente relacionado com o diagnóstico de admissão e o processo da doença (Knaus et al., 1985; Waters e Nightingale, 1990). Alguns grupos de pacientes foram excluídos da 
atualização (como queimados, crianças, infarto agudo do miocárdio e pacientes submetidos a cateterismo coronariano) e deve haver cautela se aplicado o APACHE II a esses grupos (Waters e Nightingale, 1990).

Embora tenham sido criados e validados o APACHE III e IV, a versão II continua sendo a mais utilizada devido às duas últimas versões serem comercializadas e não terem a equação de regressão para uso público (Strand e Flaatten, 2008).

\subsection{Escores Preditivos de Mortalidade em Pediatria}

Os dois principais escores de mortalidade utilizados na UTIP são o Pediatric Risk of Mortality (PRISM) e o Pediatric Index of Mortality (PIM).

O PRISM, considerado a segunda geração do escore e em alguns artigos citado como PRISM II, foi obtido a partir do Physiologic Stability Index (PSI), primeira geração do escore, que foi desenvolvido usando métodos subjetivos de coleta de dados e baseado na hipótese de que a instabilidade fisiológica é diretamente refletida em risco de mortalidade (Yeh et al., 1984; Pollack et al., 1987). O PRISM foi validado em 1988 e surgiu como um importante instrumento na terapia intensiva para prognosticar a evolução dos pacientes, separando os casos mais graves dos mais simples, reduzindo o número de variáveis fisiológicas requeridas nas UTIs e obtendo graduações dentro das variáveis remanescentes (Pollack et al., 1988). Foram avaliados 1415 pacientes de nove UTIPs dos EUA, entre 1984 e 1985, com 116 óbitos. Análises estatísticas eliminaram as categorias sem significância do PSI, diminuindo de 34 para 14 variáveis, e foram atribuídos pesos diferentes as 
mesmas, o que reflete melhor sua gravidade e contribuição no risco de óbito. O escore utiliza tanto variáveis fisiológicas (pressão arterial, frequências cardíaca e respiratória, escala de coma de Glasgow e reação pupilar), quanto laboratoriais (pressão arterial de oxigênio e gás carbônico, tempo de protrombina e tempo de tromboplastina ativada, bilirrubina, potássio, cálcio, bicarbonato e glicemia). Para cada variável é utilizado o pior valor registrado nas primeiras 24 horas de admissão; o risco de óbito é calculado mediante uma equação de regressão logística com a utilização do valor do PRISM, idade do paciente e presença ou não de cirurgia à admissão na UTIP (Anexo C). O emprego do escore não é influenciado significativamente pelo diagnóstico nem pelo estado cirúrgico do paciente. Apresenta excelente desempenho discriminatório e preditivo, sendo utilizado em muitas UTIP como indicador prognóstico para avaliação da gravidade da doença e da qualidade de atendimento (Costa et al., 2010).

O PIM2 (Slater et al., 2003), que é uma versão revisada do PIM (Shann et al., 1997), foi validado em UTIP da Nova Zelândia, Austrália e Reino Unido em 2003; foram avaliados 20.787 pacientes durante o ano de 1997, com 1104 óbitos; foi realizada regressão logística para avaliar o novo modelo que, embora tenha 11 variáveis (três a mais em relação ao PIM, que era composto por oito variáveis) mostrou ser mais bem calibrada, segura e com melhor ajuste em diferentes grupos diagnósticos, quando comparado à versão original. O risco de óbito é calculado mediante uma equação de regressão logística que utiliza as variáveis fisiológicas, estado operatório, presença de doença de base e motivo de internação na UTIP (Anexo D). 
A introdução de novos protocolos de tratamento, intervenções terapêuticas e estratégias de monitorização, além da mudança no perfil da população internada em UTIP, torna necessária a revalidação dos escores prognósticos ao longo do tempo.

O PRISM III é a terceira geração do PRISM e foi validada em 1996 (Pollack et al., 1996). Foi realizada uma coorte prospectiva em 32 UTIP nos EUA, entre 1993 e 1994, que incluíram 11.165 admissões com 543 óbitos. O risco de mortalidade pode ser calculado utilizando dados das primeiras 12 horas (PRISM III-12) ou das primeiras 24 horas de internação (PRISM III24). A regressão logística multivariada resultou em 17 variáveis fisiológicas subdivididas em 26 itens tanto para o PRISM III-12 quanto para o PRISM III24. O PRISM III-24 mostrou melhor acurácia para o risco de mortalidade individual. Mostrou-se um modelo com boa acurácia e boa capacidade de discriminação. Porém, foi o primeiro escore prognóstico pediátrico protegido por licenças e patentes, sendo que para adquirir as fórmulas e o cálculo final da probabilidade de óbito era necessário o pagamento de uma taxa institucional anual.

Em 2015, após 20 anos, houve a quebra de patente do PRISM III sendo recentemente publicado o PRISM IV (Pollack et al., 2016). Foram incluídos 10.078 pacientes de sete UTIPs dos EUA de dezembro de 2011 a abril de 2013, sendo $75 \%$ utilizados para a construção do escore e $25 \%$ para sua validação. O escore utiliza as mesmas variáveis do PRISM III (Anexo E), porém com modificações nas instruções para coleta dos dados. Pode-ser utilizar o maior e/ou menor valor das variáveis. Quando há ambos, o escore pode ser 
atribuído ao maior ou menor valor. Para as variáveis laboratoriais utilizar o período de duas horas antes até quatro horas após a admissão na UTIP. Para as variáveis fisiológicas utilizar as primeiras quatro horas após admissão na UTI. Para pacientes internados para procedimento cardíaco (cateterismo ou cirurgia), a realização do escore na admissão na UTIP ou após a cirurgia depende da idade do paciente, tempo de UTI antes do procedimento e tipo de intervenção (Anexo F). Diferentemente dos outros escores de mortalidade, orienta-se usar apenas a primeira admissão na UTIP durante a hospitalização e a alta ou óbito se refere a alta hospitalar e não a alta da UTIP. Na população em que foi validada mostrou-se com boa discriminação e calibração, sendo necessário utilizar em outras populações para haver validação externa.

O PIM 3 é uma versão recente do PIM2, para ajustar o risco de mortalidade das crianças admitidas na UTIP (Straney et al., 2013) (Anexo G). Foi realizado um estudo coorte internacional, multicêntrico e prospectivo em seis UTIPs na Austrália, Nova Zelândia, Irlanda e Reino Unido, onde foram incluídas 53.112 crianças menores de 16 anos admitidas em 2010 e 2011. Foi realizada uma regressão logística para avaliar o novo modelo que tem 10 variáveis. As variáveis com maior risco de óbito foram: valores fisiológicos anormais, presença de pupilas fixas e dilatadas e necessidade de VM na primeira hora. E aquelas com menor risco de óbito forma: admissão eletiva, recuperação de procedimento e presença de diagnósticos de baixo risco. Embora tenha apresentado uma boa discriminação global, a mesma foi melhor na Austrália e Nova Zelândia que no Reino Unido e Irlanda. Por ser recente, deve ser validado em outros estudos para avaliar sua discriminação e calibração em diferentes populações. 
Desde a criação e validação dos escores prognósticos de mortalidade, vários estudos procuraram demonstrar sua aplicabilidade na prática clínica. Alguns autores, demonstraram que o PRISM tem boa capacidade de calibração e discriminação em UTIP (Van Brakel et al., 2000; Leteurtre et al., 2001; El-Nawawy, 2003; Martha et al., 2005; Costa et al., 2010; El Karaksy et al., 2011; Garcia et al., 2011), assim como outros autores demonstraram que o PIM2 também é adequado em UTIP (Wolfler et al., 2007; Eulmesekian et al., 2007; Garcia e Piva, 2007; Ebenezer et al., 2011; Netto et al., 2011).

Os desempenhos do PRISM e do PIM ou PIM2 foram algumas vezes comparados na literatura. Martha et al. (2005) compararam o PRISM e o PIM em uma UTI pediátrica geral e concluíram que ambos tinham boa capacidade de discriminação entre sobreviventes e não sobreviventes. Slater et al. (2004) compararam o PIM, PIM 2, PRISM e PRISM III em 10 UTIP da Austrália e Nova Zelândia e demonstraram que o PIM 2 era o melhor para diferenciar os grupos de risco; porém, apenas uma dessas UTIP era de nível de atendimento terciário. Ozer et al. (2004) compararam o PRISM e o PIM em UTI pediátrica da Turquia, onde há alta taxa de mortalidade, e concluíram que o PIM seria o melhor escore para predizer a mortalidade daquela região. Leteurtre et al. (2001) demonstraram que o PRISM tem melhor performance que o PIM em crianças com choque séptico meningocócico. Trunkral et al. (2006) demonstraram que o PRISM e o PIM2 tem boa discriminação, porém ambos subestimam a mortalidade. Eulmesekian et al. (2006) demonstraram que o PIM2 tem melhor performance que o PRISM em uma UTIP heterogênea. 
Não há consenso na literatura, entre PRISM e PIM2, quanto à utilidade e padronização na admissão na terapia intensiva para as crianças e adolescentes, principalmente em uma UTI de nível de atendimento terciário (Shann et al., 1997) e não há comparação desses escores de mortalidade em pacientes heterogêneos em UTI pediátrica de nível de atendimento terciário, com alta taxa de complexidade e mortalidade.

\subsection{Avaliação de um Sistema de Escore}

O desenvolvimento de um sistema de escore requer clareza, facilidade, variáveis relevantes, aderência a uma metodologia padrão e especificidade possibilitando com isso uma melhor monitorização do quanto estamos cuidando dos pacientes que internam nas UTIPs.

Para quantificar a qualidade dos cuidados prestados na UTIP por meio do escore de mortalidade utiliza-se o Standardized Mortality Ratio (SMR), que é um teste estatístico que compara a estimativa de mortes com

a realidade da UTIP avaliada (Glance et al., 2000). É feito por meio da divisão do número de mortes observadas pelo número de mortes esperadas. Se o valor do SMR for menor que 1, o escore superestimou a realidade da UTIP, ou seja, ocorreram menos mortes do que a prevista pelo escore. Se o valor for maior que 1 , o escore subestimou a realidade, ou seja, morreram mais pacientes que o previsto pelo escore.

A performance do escore é obtida por meio do cálculo da discriminação e calibração. A discriminação é a habilidade do modelo em distinguir os pacientes que irão sobreviver daqueles que irão morrer e é 
obtida a partir do cálculo da área sob a curva Receiver Operating Characteristics (ROC). A curva ROC é uma curva formulada a partir da sensibilidade (predição de morte) e da especificidade (predição de alta) de cada paciente avaliado. A área abaixo da curva ROC garante a capacidade discriminatória do escore avaliado (Hanley e McNeil, 1982). Um teste com poder preditivo perfeito é representado por $100 \%$ de sensibilidade e taxa de erro falso positivo de $0 \%$, resultando em uma área sob a curva ROC de 1 (Hanley e McNeil, 1983). Uma área sob a curva ROC entre 0,7-0,79 é considerada aceitável, valores de 0,8 - 0,89 são considerados bons, e 0,9 ou mais são excelentes (Shann, 2002).

A calibração é a acurácia do risco de morte previsto e é calculada por meio do qui-quadrado de Hosmer-Lemeshow para comparar a mortalidade real com a prevista do escore em diferentes intervalos de risco. O teste divide os pacientes em grupos de acordo com sua gravidade, e, com isso, compara-se o número de mortes observadas com o numero de mortes prevista. $O$ resultado do teste apresenta boa calibração se $o$ valor de $p$ for maior que 0,05 sendo que quanto maior o valor de $p$ melhor é o ajuste do modelo (Lemeshow et al., 1982). 


\subsection{Justificativa}

A utilização de um escore de mortalidade adequado, que reflita a gravidade dos pacientes admitidos na UTIP é fundamental para a avaliação da qualidade do atendimento prestado. A validação de escores consagrados na literatura em outras populações, que não a do escore original, é legítima segundo os próprios autores do escore ${ }^{1}$. Não há consenso na literatura de qual o melhor escore de mortalidade para ser utilizado em UTIP terciária sendo necessária a avaliação do comportamento dos dois escores mais utilizados na literatura nessa população.

\subsection{Hipótese}

Em uma unidade de terapia intensiva pediátrica terciária há diferença na previsão do risco de morte entre dois escores de avaliação de gravidade reconhecidos e validados (PRISM e PIM2), frequentemente utilizados nas unidades de terapia intensiva para crianças e adolescentes.

\footnotetext{
${ }^{1}$ Comunicação pessoal. Dr. Murray Pollack via email em 4 de novembro de 2015.
} 
2 Objetivos 


\subsection{Geral}

Estabelecer o escore de melhor performance na avaliação do prognóstico de mortalidade (por meio do SMR, discriminação e calibração), que seja facilmente aplicável na rotina da UTIP, para ser utilizado de forma padronizada e contínua.

\subsection{Específicos}

a) Avaliar e comparar o grau de gravidade e prognóstico dos pacientes nas primeiras 24 horas de internação utilizando os escores PRISM e PIM2, em uma UTIP de nível de atendimento terciário.

b) Comparar o grau de concordância entre os escores.

c) Comparar a mortalidade real com a prevista a partir de cada escore. 
3 Métodos 


\subsection{Casuística}

Foram revisados os escores PRISM e PIM2 de 398 pacientes internados na unidade de terapia intensiva pediátrica do Instituto da Criança do Hospital das Clínicas da Faculdade de Medicina da USP, considerada uma unidade de atendimento de nível terciário (Portaria $n^{0}$ 3.432/MS/GM, de 12 de agosto de 1998), referência para doenças pediátricas de alta complexidade, tanto clínicas quanto cirúrgicas, com 15 leitos, que atende crianças de um mês a 18 anos.

O número de casos da amostra foi estimado em 300 pacientes considerando uma mortalidade de $15 \%$ e tolerando-se uma variação de mortalidade entre $10 \%$ e $20 \%$ com erro a de 0,05 e poder do estudo de $80 \%$.

Os prontuários dos pacientes foram analisados retrospectivamente e 0 critério de inclusão foi a análise de todos os pacientes consecutivamente admitidos na UTI no período do estudo. Os critérios de exclusão foram: pacientes que evoluíram a óbito nas primeiras oito horas após a internação ou que receberam alta da UTI nas primeiras 24 horas. 


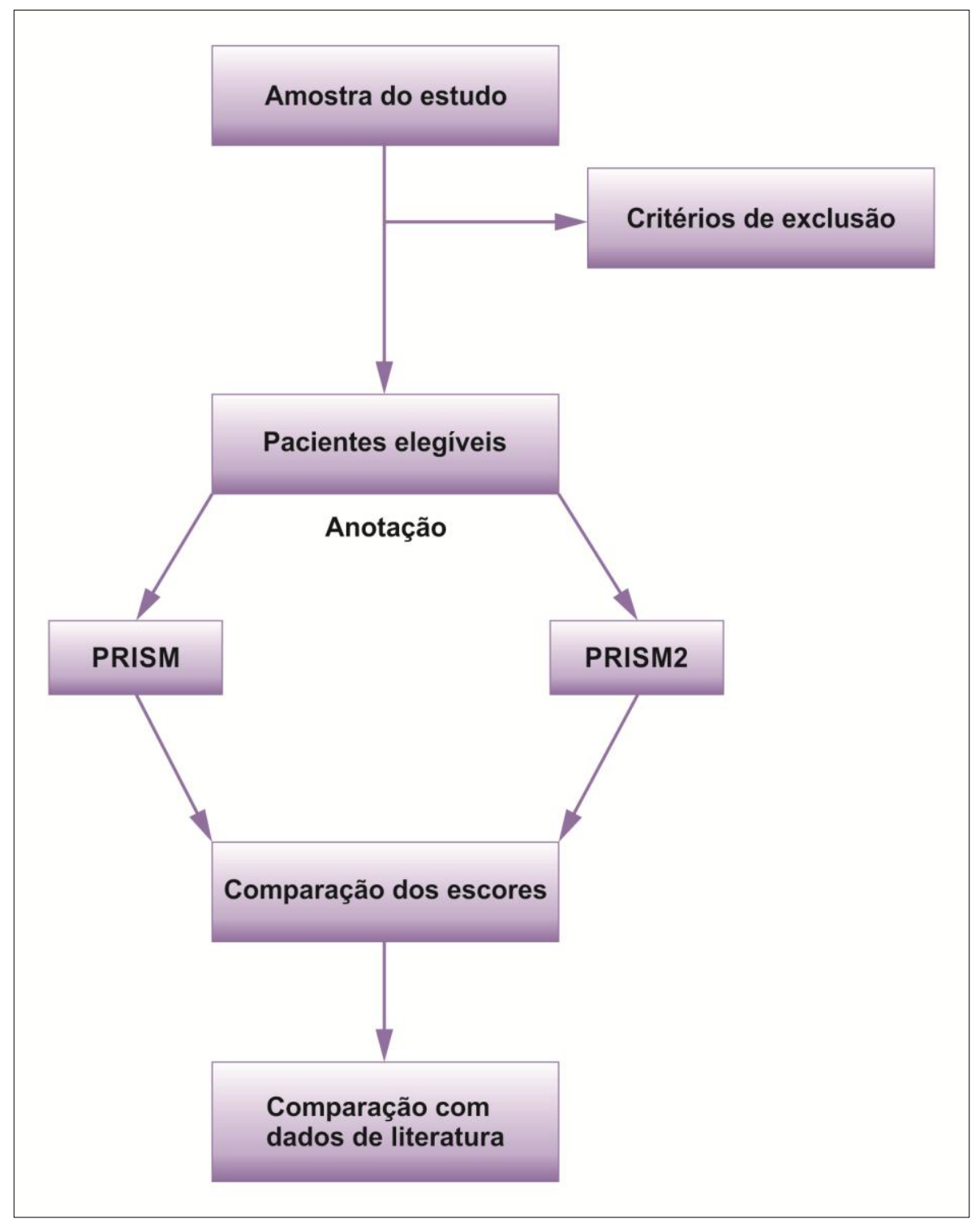

Figura 1 - Desenho do estudo

\subsection{Metodologia}

Por meio de uma coorte retrospectiva foi realizada análise de prontuários e anotados os resultados dos escores PRISM e PIM2 aplicados rotineiramente pela equipe médica em todos os pacientes internados consecutivamente na UTIP, nas primeiras 24 horas de internação, no período de abril de 2007 a abril de 2008. Todos os escores foram revisados sistematicamente pelo mesmo profissional (autora da tese). 
Para o cálculo do PRISM foram utilizadas as 14 variáveis do escore original (pressão arterial sistólica, pressão arterial diastólica, frequência cardíaca, frequência respiratória, relação da pressão arterial de oxigênio pela fração inspirada de oxigênio, pressão parcial arterial de gás carbônico, escala de coma de Glasgow, reação pupilar, razão do tempo de protrombina, bilirrubina total, dosagem sérica de potássio e cálcio, glicemia e bicarbonato sérico). Foi utilizado o pior valor de cada parâmetro nas primeiras 24 horas de internação na UTIP.

O PIM2 foi calculado com base nas 11 variáveis do escore original (admissão eletiva, presença de patologia de alto risco, presença de patologia de baixo risco, reação pupilar, excesso de base arterial, pressão parcial arterial de oxigênio, fração inspirada de oxigênio, pressão arterial sistólica, uso de ventilação mecânica, admissão pós-operatória, uso de circulação cardíaca extracorpórea). Os dados foram coletados na primeira hora de admissão na UTIP.

Foram também anotados os dados demográficos da população: idade (meses), gênero (feminino ou masculino), motivo principal da admissão na UTIP (pós-operatório, sepse/choque séptico, respiratório, neurológico, monitorização, outros), presença de doença crônica complexa (DCC), dias de internação na UTIP, morbidade (uso de ventilação mecânica e drogas vasoativas) e desfecho (alta ou óbito).

Foi realizada análise da literatura por meio de pesquisa sistemática no Medline, Embase e Lilacs, comparando estudos semelhantes que serviram como subsídio para a discussão dos resultados. 
Todos os dados foram coletados em planilhas do tipo Microsoft Excel (Anexo H). A mediana do escore e a porcentagem do risco de óbito (média e desvio padrão) foram analisadas utilizando planilha STATA versão 7.0 (STATA Corporation, College Station, TX). Foram consideradas diferenças estatisticamente significantes quando $p<0,05$. A correlação quantitativa entre os resultados dos escores foi analisada por meio da correlação de Spearman.

O risco de mortalidade de ambos os escores foi realizado utilizando a equação de regressão logística dos artigos originais, disponíveis publicamente na página da Sociedade Francesa de Anestesia e Reanimação (Société Française d'Anesthésie et de Réanimation²).

A performance de ambos os escores (PRISM e PIM2) foi avaliada por meio do SMR, discriminação e calibração. O SMR faz uma avaliação geral da unidade comparando a mortalidade observada com a esperada de cada escore. A discriminação foi avaliada por meio da curva ROC e estima a probabilidade de concordância entre o desfecho e o previsto, isto é, a habilidade do modelo de diferenciar os pacientes que irão morrer daqueles que irão sobreviver. A calibração foi calculada por meio do teste de qui-quadrado de Hosmer-Lemeshow que obtém o resultado dos óbitos observados pelos esperados, divididos em quartis de risco. Esse teste é calculado pela fórmula $\Sigma$ $\left(O-E^{2} / E\right)$, onde $O$ é a mortalidade observada e $E$ o número de óbitos esperados pelo escore, sendo considerado significativo valores de $p>0,05$ e, quanto maior o valor de $\mathrm{p}$, melhor a calibração do escore.

\footnotetext{
${ }^{2}$ Disponível em: <http://www.sfar.org>.
} 
O estudo foi aprovado pela Comissão de Ética para Análise de Projetos de Pesquisa (CAPPesq) da Diretoria Clínica do Hospital das Clínicas e da Faculdade de Medicina da Universidade de São Paulo (Protocolo de pesquisa $n^{0}$ 0912/08) (Anexo I). Por se tratar de revisão de dados de prontuário, foi desnecessário o uso do termo de consentimento livre e esclarecido, sendo firmado compromisso em se manter sigilo quanto à identificação dos pacientes e dados obtidos. 
4 Resultados 
Durante o período do estudo ocorreram 398 admissões na UTIP, entretanto, 36 pacientes foram excluídos: 10 pacientes foram a óbito nas primeiras oito horas, 26 pacientes receberam alta nas primeiras 24 horas e três pacientes foram excluídos por falta de dados no prontuário. Portanto, 359 pacientes foram incluídos no estudo com 54 óbitos (15\%) (Figura 2).

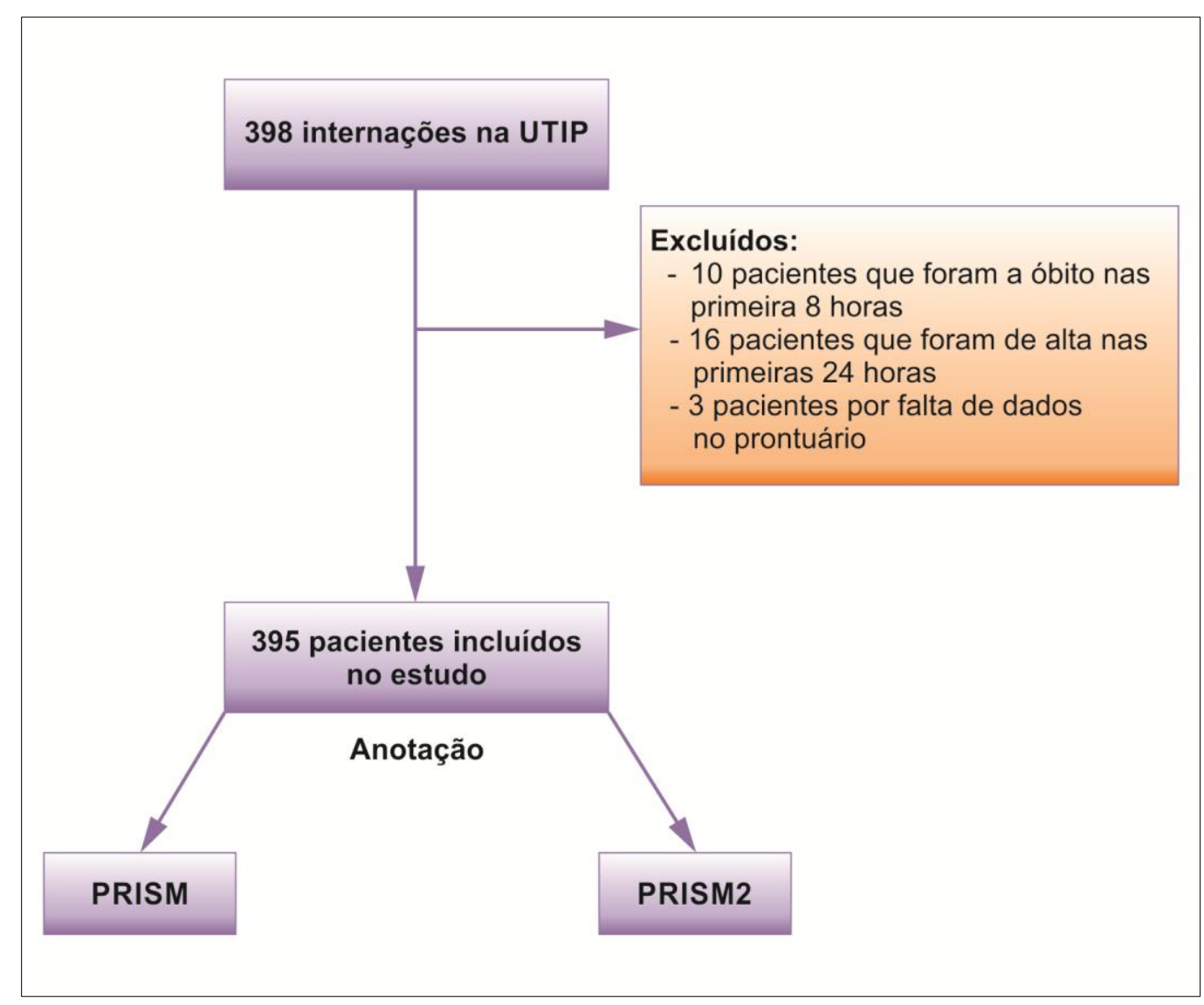

Figura 2 - Fluxograma do estudo 
O principal tipo de admissão foi clinico (78\%) sendo a principal causa de internação a disfunção respiratória (37,3\%) (Tabela 1).

Tabela 1 - Características dos pacientes do estudo

\begin{tabular}{|c|c|c|}
\hline Variáveis & $\mathrm{n} \%(\%)$ & $\begin{array}{c}\text { Mediana } \\
\text { (P25 - P75) }\end{array}$ \\
\hline Total de pacientes & 359 & \\
\hline Idade (meses) & & $31(11-94)$ \\
\hline Dias de internação na UTIP & & $5(3-10)$ \\
\hline \multicolumn{3}{|l|}{ Gênero } \\
\hline Masculino & $198(55)$ & \\
\hline Feminino & $161(45)$ & \\
\hline \multicolumn{3}{|l|}{ Tipo de paciente } \\
\hline Clínico & $280(78)$ & \\
\hline Cirúrgico & $79(22)$ & \\
\hline \multicolumn{3}{|l|}{ Presença de DCC (principal) } \\
\hline $\mathrm{N}$ & $49(14)$ & \\
\hline S & $310(86)$ & \\
\hline Hepática & $70(23)$ & \\
\hline Oncológica & $60(19)$ & \\
\hline Neurológica & $49(16)$ & \\
\hline Respiratória & $34(11)$ & \\
\hline Outras & 97 (31) & \\
\hline \multicolumn{3}{|l|}{ Ventilação Mecânica } \\
\hline $\mathrm{N}$ & $134(37)$ & \\
\hline S & $225(63)$ & \\
\hline \multicolumn{3}{|l|}{ Drogas vasoativas } \\
\hline $\mathrm{N}$ & $231(65)$ & \\
\hline S & $128(35)$ & \\
\hline 1 droga & $60(47)$ & \\
\hline 2 drogas & $31(24)$ & \\
\hline$\geq 3$ drogas & $37(29)$ & \\
\hline Óbitos & $54(15)$ & \\
\hline
\end{tabular}

$\mathrm{N}=$ não; $\mathrm{S}=\operatorname{sim} ; \mathrm{DCC}=$ doença crônica complexa

Os escores dos pacientes que foram a óbito mostraram-se maiores do que o dos sobreviventes. Para o PRISM foi 15 versus $7(p=0,0001)$ e para o PIM2, 11 versus $5(p=0,0002)$, respectivamente (Tabela 2). 
Tabela 2 - Comparação do PRISM e PIM2 entre pacientes que foram a óbito e sobreviventes

\begin{tabular}{lcccc}
\hline \multicolumn{1}{c}{ Pacientes } & $\begin{array}{c}\text { PRISM } \\
\text { Mediana } \\
(\text { P25-P75) }\end{array}$ & $p$ & $\begin{array}{c}\text { PIM2 } \\
\text { Mediana } \\
(\text { P25-P75) }\end{array}$ & p \\
\hline Geral & $8(4-14)$ & & $6(2-16)$ & \\
Óbito & $15(8-21)$ & $\mathbf{0 , 0 0 0 1}^{*}$ & $11(4-24)$ & $\mathbf{0 , 0 0 0 2}$ \\
Sobrevivente & $7(3-12)$ & & $5(1-14)$ & \\
\hline
\end{tabular}

* $p$ entre pacientes que foram à óbito e sobreviveram; teste Mann-Whitney

Para a amostra geral, o SMR (intervalo de confiança 95\%) usando o PIM2 foi de $1,15(0,84-1,46)$ e para o PRISM foi de $1,67(1,23-2,11)$. 0 SMR para subgrupos de idade e tipo de paciente (cirúrgico ou clinico) é mostrado na Tabela 3.

Tabela 3 - Standardized Mortality Ratio (SMR) dos escores PRISM e PIM2 para subgrupos de idade e tipo de paciente (cirúrgico ou clínico)

\begin{tabular}{lcccccc} 
& \multicolumn{2}{c}{ Pacientes } & \multicolumn{2}{c}{ PRISM } & \multicolumn{2}{c}{ PIM2 } \\
& $\mathbf{n}$ & $\%$ & SMR & $95 \%$ CI & SMR & $95 \%$ CI \\
\hline Idade & & & & & & \\
$<1$ ano & 104 & 29,0 & 1,52 & $0,69-2,35$ & 0,90 & $0,42-1,38$ \\
\hline $1-4$ anos & 129 & 35,9 & 1,66 & $0,98-3,32$ & 1,47 & $0,87-2,07$ \\
\hline $5-10$ anos & 65 & 18,1 & 1,84 & $0,57-3,11$ & 0,95 & $0,29-1,61$ \\
\hline$\geq 10$ anos & 61 & 17,0 & 1,75 & $0,66-2,84$ & 1,24 & $0,47-2,01$ \\
\hline Tipo de paciente & & & & & & \\
Cirúrgico & 79 & 22,0 & 1,32 & $0,34-2,30$ & 1,28 & $0,33-2,23$ \\
\hline Clínico & 280 & 78,0 & 1,73 & $1,24-2,22$ & 1,14 & $0,82-1,46$ \\
\hline
\end{tabular}

O teste de Hosmer-Lemeshow mostrou $x^{2}=12,96(p=0,11)$ para 0 PRISM e $x^{2}=13,7(p=0,09)$ para o PIM2. A Tabela 4 mostra a calibração para os subgrupos idade, tempo de internação na UTIP e motivo principal da admissão por meio do mesmo teste. 
Tabela 4 - Calibração dos escores PRISM e PIM2 para os subgrupos idade, tempo de internação na UTIP e motivo principal da admissão por meio do teste de Hosmer-Lemeshow

\begin{tabular}{|c|c|c|c|c|c|c|}
\hline \multirow{2}{*}{ Subgrupos } & \multicolumn{2}{|c|}{ Pacientes } & \multicolumn{2}{|c|}{ PRISM } & \multicolumn{2}{|c|}{ PIM2 } \\
\hline & $n$ & $\%$ & $x^{2}$ & p & $x^{2}$ & $p$ \\
\hline \multicolumn{7}{|l|}{ Idade } \\
\hline$<1$ ano & 104 & 29,0 & 7,54 & 0,47 & 14,46 & 0,07 \\
\hline $1-4$ anos & 129 & 35,9 & 11,62 & 0,16 & 4,93 & 0,76 \\
\hline $5-10$ anos & 65 & 18,1 & 6,11 & 0,63 & 7,91 & 0,44 \\
\hline$\geq 10$ anos & 61 & 17,0 & 0,31 & 0,99 & 11,76 & 0,16 \\
\hline \multicolumn{7}{|c|}{ Tempo de internação na UTI } \\
\hline$<3$ dias & 77 & 21,4 & 3,31 & 0,85 & 13,55 & 0,09 \\
\hline $3-6$ dias & 126 & 35,1 & 6,94 & 0,54 & 11 & 0,20 \\
\hline$>6$ dias & 156 & 43,5 & 6,01 & 0,64 & 3,65 & 0,88 \\
\hline \multicolumn{7}{|c|}{ Causa principal da internação na UTIP } \\
\hline Pós-operatório & 79 & 22,0 & 6,46 & 0,59 & 13,87 & 0,08 \\
\hline Sepse/Choque séptico & 44 & 12,3 & 6,48 & 0,59 & 9 & 0,34 \\
\hline Respiratório & 134 & 37,3 & 5,28 & 0,72 & 7,69 & 0,46 \\
\hline Neurológico & 34 & 9,5 & * & * & 6,89 & 0,54 \\
\hline Monitorização & 31 & 8,6 & 1,72 & 0,88 & 6,53 & 0,58 \\
\hline Outros & 37 & 10,3 & 6,4 & 0,6 & 9,88 & 0,27 \\
\hline
\end{tabular}

A discriminação foi realizada por meio da área sob a curva ROC sendo que para o PRISM esse valor foi de 0,76 (IC 95\% 0,69 - 0,83) e para o PIM2 0,65 (IC 95\% 0,57 - 0,72), p=0,002 (Gráfico 1). A Tabela 5 mostra a comparação da discriminação para os subgrupos idade, tempo de internação na UTIP e motivo principal da admissão pelo mesmo método. 
Gráfico 1 - Comparação da discriminação do PRISM e PIM2 por meio da área sob a curva ROC

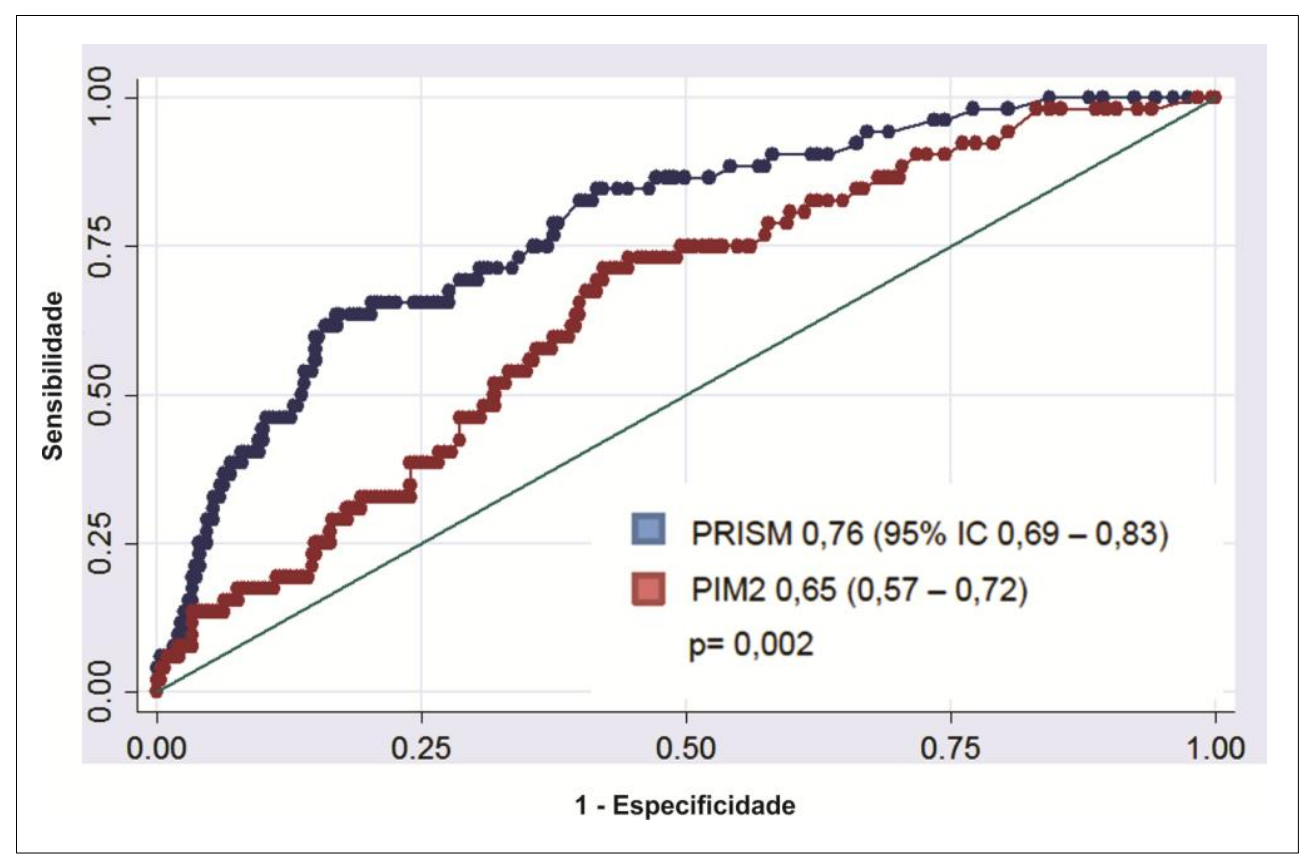

Tabela 5 - Comparação da discriminação do PRISM e PIM2 para os subgrupos idade, tempo de internação na UTIP e motivo principal da admissão por meio da área sob a curva ROC

\begin{tabular}{|c|c|c|c|c|c|}
\hline \multirow[b]{2}{*}{ Subgrupos } & \multicolumn{2}{|c|}{ PRISM } & \multicolumn{2}{|c|}{ PIM2 } & \multirow[b]{2}{*}{ p } \\
\hline & $\begin{array}{c}\text { Curva } \\
\text { ROC }\end{array}$ & IC 95\% & $\begin{array}{c}\text { Curva } \\
\text { ROC }\end{array}$ & IC $95 \%$ & \\
\hline \multicolumn{6}{|l|}{ Idade } \\
\hline$<1$ ano & 0,69 & $0,51-0,86$ & 0,65 & $0,50-0,79$ & 0,73 \\
\hline $1-4$ anos & 0,66 & $0,55-0,78$ & 0,62 & $0,50-0,74$ & 0,56 \\
\hline $5-10$ anos & 0,73 & $0,52-0,93$ & 0,57 & $0,37-0,77$ & 0,30 \\
\hline$\geq 10$ anos & 0,99 & $0,97-1,00$ & 0,83 & $0,71-0,95$ & 0,009 \\
\hline \multicolumn{6}{|c|}{ Tempo de internação na UTIP } \\
\hline$<3$ dias & 0,91 & $0,78-1,00$ & 0,79 & $0,61-0,97$ & 0,08 \\
\hline $3-6$ dias & 0,87 & $0,75-0,99$ & 0,78 & $0,68-0,88$ & 0,19 \\
\hline$>6$ dias & 0,64 & $0,53-0,74$ & 0,51 & $0,68-0,88$ & 0,07 \\
\hline \multicolumn{6}{|c|}{ Causa principal de internação na UTIP } \\
\hline Pós-operatório & 0,87 & $0,76-0,98$ & 0,87 & $0,76-0,98$ & 0,97 \\
\hline Sepse/Choque séptico & 0,64 & $0,47-0,81$ & 0,51 & $0,33-0,68$ & 0,17 \\
\hline Respiratório & 0,68 & $0,54-0,83$ & 0,65 & $0,53-0,77$ & 0,70 \\
\hline Neurológico & 1,00 & $1,00-1,00$ & 0,67 & $0,08-1,00$ & 0,27 \\
\hline Monitorização & 0,89 & $0,70-1,00$ & 0,58 & $0,16-0,99$ & 0,13 \\
\hline Outros & 0,52 & $0,22-0,82$ & 0,39 & $0,09-0,69$ & 0,50 \\
\hline
\end{tabular}


A Tabela 6 mostra a sensibilidade e especificidade das diversas pontuações do PRISM.

Tabela 6 - Sensibilidade e Especificidade das diversas pontuações do PRISM

\begin{tabular}{|c|c|c|c|c|c|}
\hline Pontuação & S (\%) & E (\%) & Pontuação & S (\%) & $E(\%)$ \\
\hline$\geq 0$ & 100 & 0 & $\geq 17$ & 46,30 & 88,85 \\
\hline$\geq 1$ & 100 & 11,48 & $\geq 18$ & 40,74 & 91,80 \\
\hline$\geq 2$ & 100 & 14,43 & $\geq 19$ & 37,04 & 93,44 \\
\hline$\geq 3$ & 96,30 & 22,62 & $\geq 20$ & 25,93 & 94,75 \\
\hline$\geq 4$ & 90,74 & 26,56 & $\geq 21$ & 25,93 & 96,07 \\
\hline$\geq 5$ & 87,04 & 34,10 & $\geq 22$ & 24,07 & 96,39 \\
\hline$\geq 6$ & 85,19 & 40,66 & $\geq 23$ & 20,37 & 97,38 \\
\hline$\geq 7$ & 85,19 & 45,90 & $\geq 25$ & 12,96 & 97,70 \\
\hline$\geq 8$ & 83,33 & 52,46 & $\geq 26$ & 9,26 & 98,36 \\
\hline$\geq 9$ & 74,07 & 57,05 & $\geq 27$ & 5,56 & 99,02 \\
\hline$\geq 10$ & 70,37 & 63,93 & $\geq 31$ & 5,56 & 99,34 \\
\hline$\geq 11$ & 66,67 & 67,54 & $\geq 37$ & 5,56 & 99,67 \\
\hline$\geq 12$ & 66,67 & 70,16 & $\geq 40$ & 3,70 & 99,67 \\
\hline$\geq 13$ & 66,67 & 75,74 & $\geq 41$ & 3,70 & 100 \\
\hline$\geq 14$ & 64,81 & 79,67 & $\geq 43$ & 1,85 & 100 \\
\hline$\geq 15$ & 57,41 & 82,95 & $>43$ & 0 & 100 \\
\hline$\geq 16$ & 48,15 & 86,23 & & & \\
\hline
\end{tabular}

$\mathrm{S}=$ sensibilidade $; \mathrm{E}=$ especificidade 
5 Discussão 
Em 1996, Donabedian, considerado o precursor da avaliação da qualidade nos serviços de saúde, propôs que a mensuração dos mesmos deveria ser considerada em três dimensões: estrutura, processo e resultados. Embora a estrutura e os processos na UTIP possam ser medidos objetivamente, a interpretação e mensuração dos resultados, especialmente mortalidade, não é uma tarefa simples (Lopez et al., 2015). Para realizar comparações de mortalidade local, regional ou internacional e devido às diferenças nas características de tratamento dos pacientes, é necessário ajustar o risco de óbito a fatores que possam influenciar os resultados por meio da utilização dos escores prognósticos de mortalidade (Espuñes et al., 2007).

Os sistemas de escores, especialmente aqueles que medem a gravidade da doença, como os escores prognósticos de mortalidade, ajudam na compreensão e até mesmo na resolução de problemas, quantificando dados clínicos que de outra maneira seriam difíceis de serem resumidos objetivamente. A maioria desses escores objetiva medir a gravidade da doença, seja diretamente pelas alterações fisiológicas ou indiretamente por marcadores como terapias ou diagnósticos, calibrando essas observações quantitativas a um determinado desfecho, na maioria das vezes óbito ou sobrevida (Pollack, 2015). 
O ajuste da mortalidade por estado fisiológico e/ou outras variáveis (idade, dados laboratoriais, etc.) tem sido a principal metodologia aplicada nas UTIs neonatal, pediátrica e de adultos nas últimas décadas com a intenção de promover melhora da qualidade de atendimento por meio da comparação de referenciais internos e externos (benchmarking) (Pollack et al., 2015).

O presente estudo, que foi realizado em uma UTIP terciária, predominantemente clínica, com $86 \%$ dos pacientes portadores de doença crônica complexa e $15 \%$ de mortalidade, mostrou que pacientes que foram a óbito tiveram os escores prognósticos de mortalidade (tanto PRISM quanto PIM2) significativamente maiores que aqueles que sobreviveram, semelhante ao encontrado por Espuñes et al. (2007), que se diferenciou por uma mortalidade menor $(4,1 \%)$.

Ao comparar os resultados da discriminação de ambos os escores, o PRISM foi superior ao PIM2 na população geral [área abaixo da curva ROC $0,76(0,69-0,83)$ e $0,65(0,57-0,72)$, respectivamente, $p=0,002]$, porém tiveram desempenhos semelhantes quando analisados em subgrupos, exceto para pacientes com idade igual ou superior a 10 anos, onde o PRISM se mostrou superior ao PIM2 $(p=0,009)$.

Shann et al. criaram e validaram o PIM (primeira versão), em 1997, com um escore mais simples e de fácil aplicabilidade, uma vez que utiliza dados da primeira hora da admissão e apenas uma gasometria arterial em suas variáveis. Para isso, analisou os dados de 1587 crianças menores de 16 anos em um hospital na Austrália comparando os resultados do PIM quando realizado na primeira hora após a admissão com aqueles relacionados às primeiras 24 horas, e observou que a área abaixo da curva 
ROC foi de 0,877 e de 0,910 , respectivamente, sugerindo que 0 uso de indicadores das primeiras 24 horas pode aumentar a área sob a curva ROC em pelo menos $3 \%$ a $4 \%$. Portanto, o PRISM, que utiliza os dados das primeiras 24 horas da admissão, poderia ter uma área sob a curva ROC 3\% a $4 \%$ superior a do PIM e, nesses casos, o aumento das taxas de mortalidade seria atribuída à gravidade dos pacientes e não à qualidade do atendimento. No presente estudo, a área sob a curva ROC do PRISM foi $14,4 \%$ maior que a do PIM2, demonstrando que o PRISM tem superioridade discriminatória em relação ao PIM2.

No estudo de Leteurtre et al. (2001) realizado na França, foram incluídos 58 pacientes com choque séptico por meningococo, com mortalidade de 27,6\% e demonstrou que o PRISM teve uma melhor discriminação que o PIM [área abaixo da curva ROC 0,96 $(0,02)$ e $0,83(0,06)$, respectivamente].

O estudo de Martha et al. (2005), realizado em uma UTIP do Rio Grande do Sul, incluiu 421 pacientes com mortalidade de 7,8\%, o tipo de internação mais frequente foi o clínico (56\%) e demonstrou que tanto o PRISM quanto o PIM2 tiveram boa discriminação [área abaixo da curva ROC $0,87(0,78-0,92)$ e $0,85(0,78-0,91)$, respectivamente].

Dois estudos indianos, Thunkral et al. (2006) e Taori et al. (2010), mostraram mortalidade elevada ( $24 \%$ e $32 \%$, respectivamente), com adequada discriminação tanto para o PIM quanto para o PRISM.

Ozer et al. (2004) realizaram um estudo em um hospital universitário na Turquia onde foram incluídos 105 pacientes não cirúrgicos com uma mortalidade de $27,6 \%$ e demonstrou que nenhum dos dois escores (PRISM e PIM - primeira versão) teve discriminação adequada para aquela população. 
A estimativa dos óbitos medida pelo SMR demonstrou que ambos os escores subestimaram a mortalidade na população geral $[1,67$ (Cl 95\% 1,23 - 2,11) para o PRISM e 1,15 $(0,84$ - 1,46) para o PIM2]. Quando analisados em subgrupos, o PRISM subestimou a mortalidade para todas as faixas etárias e tipo de paciente de modo semelhante ao PIM2 exceto para aqueles entre um a quatro anos e maiores que 10 anos, onde o PIM2 superestimou a mortalidade. Devemos levar em consideração que ambos os escores foram criados e validados em populações diferentes daquela do presente estudo há alguns anos (27 anos para o PRISM e 19 anos para o PIM2) e, atualmente, o número de crianças e adolescentes com doenças preexistentes pode influenciar a diferença entre mortalidade observada e esperada. Analisando a população do presente estudo, a mortalidade subestimada não se deve à escassez de recursos humanos ou tecnológicos uma vez que o dimensionamento da equipe multidisciplinar e do parque tecnológico da UTIP em questão está de acordo com as normas vigentes no país. Além disso, todos os subgrupos de ambos os escores apresentaram intervalo de confiança amplo e incluíram o valor 1, provavelmente pelo número pequeno de pacientes em cada categoria.

Em relação à calibração, realizada pelo teste de Hosmer-Lemeshow, ambos os escores apresentaram calibração adequada tanto para a população geral $\left[x^{2}=12,96(p=0,11)\right.$ para o PRISM e $x^{2}=13,7(p=0,09)$ para o PIM2], quando analisados em subgrupos (faixa etária, período de internação e diagnósticos de admissão), com p> 0,05. Esses achados foram diferentes dos encontrados por Lopez et al. (2015) onde a calibração do PIM2 foi inadequada $\left[x^{2}=121,87(p<0,001)\right]$. 
Lopez et al. (2015) realizaram um estudo multicêntrico, prospectivo e observacional em 34 UTIP de nove países da América Latina para avaliar a capacidade do PIM2 em predizer a mortalidade nessa população. Foram incluídos 7391 pacientes com uma mortalidade de $8,97 \%$ que foi subestimada pelo SMR [1,15 (Cl 95\% 1,07 - 1,25)]. Quando analisados em subgrupos, o SMR subestimou a mortalidade no grupo de pacientes de um a 11 meses e de 13 a 16 anos, nos pacientes em pós-operatório e na presença de DCC. Esse achado corrobora o encontrado no nosso estudo, em que o SMR subestimou a mortalidade na população geral na qual $86 \%$ tinham DCC assim como em outro estudo brasileiro realizado por Fonseca e Ferreira (2014).

Adicionalmente Lopez et al. (2015) demonstraram que o PIM2 apresentou boa capacidade de discriminação para a população geral e para os subgrupos de idade, pós-operatório e presença de DCC.

Diferentemente do estudo em questão onde o PIM2 mostrou uma discriminação inadequada com uma calibração adequada, outros estudos realizados na Itália (Wolfler et al., 2007), Argentina (Eulmesekian et al., 2007; Canonero et al., 2010; Fernández et al., 2015), Barbados (Hariharan et al., 2011), Brasil (Lima Netto et al., 2014), Croácia (Mestrovic et al., 2005), Índia (Thunkral et al., 2006), Japão (Imamura et al., 2012) e Irã (Salamanti et al., 2012) mostraram uma boa discriminação do PIM2 com calibração variável de acordo com cada região, denotando a influência da localização na performance do escore.

Apesar de não haver comparação entre PIM2 e PRISM nos trabalhos supracitados, os escores de gravidade podem ter seus resultados 
modificados em consequência: do sistema de saúde (público ou privado), da infraestrutura da UTIP (número de leitos, recursos humanos, parque tecnológico) e indicação da internação. Essas diferenças de discriminação e calibração encontradas de um estudo para o outro devem ser interpretadas considerando que qualquer modelo utilizado para predizer o risco de mortalidade deve incluir aqueles fatores que influenciam no prognóstico e devem ser calibrados de maneira adequada para aquela população.

A presença de DCC não é levada em consideração nas variáveis do PRISM, mas estudo anterior de Costa et al. (2010), realizado na mesma população, mostra que a presença de DCC não é fator de risco para o PRISM, após regressão logística univariada. Embora o PIM2 leve em consideração algumas condições como fatores de risco para mortalidade (Anexo D), não há prevalência de DCC na amostra onde o escore foi desenvolvido. Portanto, a presença de doença preexistente na nossa população pode ser uma das causas da diferença de discriminação entre ambos os escores. Além disso, há diferenças de limitação de cuidados assim como critérios de admissão entre as diferentes regiões e, principalmente, entre países desenvolvidos e em desenvolvimento.

Valores de PRISM acima de 10 são considerados para pacientes mais graves e, consequentemente, de alto risco para óbito (Costa et al., 2010). No presente estudo, a melhor sensibilidade e especificidade para esse risco seria um PRISM entre 13 e 14, mostrando que, com o avanço tecnológico, o paciente precisa ter um escore mais elevado, ou seja, maior gravidade clínica do que a população original, para um maior risco de mortalidade. 
Não existe consenso sobre qual função seria mais importante em um escore prognóstico: calibrar ou discriminar. Para uma avaliação global do escore ambos devem ser considerados. Porém, se o objetivo for distinguir aqueles com maior chance de morrer daqueles com maior chance de sobreviver, a capacidade de discriminação é mais importante; entretanto, se o objetivo da utilização do escore for comparar a mortalidade observada com a esperada em diferentes intervalos de gravidade, a capacidade de calibrar seria mais relevante (Martha et al., 2005).

A escolha de um escore de gravidade depende das características individuais da UTIP, como o tempo de espera na emergência, presença de doença crônica complexa (por exemplo, pacientes oncológicos) e como é realizado o transporte para a UTIP. Infelizmente, nos países em desenvolvimento há uma grande dificuldade na obtenção de leitos em UTIP e o transporte não é satisfatório em muitos casos, o que poderia comprometer a coleta de dados na primeira hora de admissão. Idealmente, estudos multicêntricos têm maior significância estatística. No entanto, estudos com populações maiores e mais homogêneas, especialmente nos países em desenvolvimento, são difíceis de serem realizados.

Embora haja versões mais recentes de ambos os escores, PIM3 e PRISM IV, seu uso ainda não está implementado na maioria das UTIP e precisam ser validados em contextos diferentes daqueles obtidos na população original. 


\subsection{Vantagens do Estudo}

Primeiro estudo realizado em uma amostra heterogênea de pacientes internados em UTIP de nível de atendimento terciário de um país em desenvolvimento, predominantemente clínica com alta taxa de mortalidade (15\%) para comparar a utilização de dois escores prognósticos frequentemente utilizados em terapia intensiva pediátrica.

\subsection{Limitações}

As limitações do estudo foram:

- Realizado em um único centro.

- Pequeno número de pacientes em cada subgrupo.

- Reduzido número de óbitos. 
6 CONCLUSÕES 
a) O PRISM apresentou melhor discriminação que o PIM2.

b) Ambos os escores apresentaram boa calibração.

c) Para ambos os escores, os pacientes que evoluíram a óbito apresentaram valores superiores aqueles que sobreviveram.

d) Tanto PRISM quanto PIM2 subestimaram a mortalidade real com a prevista da população geral pelo Standardized Mortality Ratio.

e) O presente estudo sugeriu que o escore PRISM foi o mais adequado para ser utilizado em pacientes internados em UTIP de nível de atendimento terciário. 


\section{ANEXos}



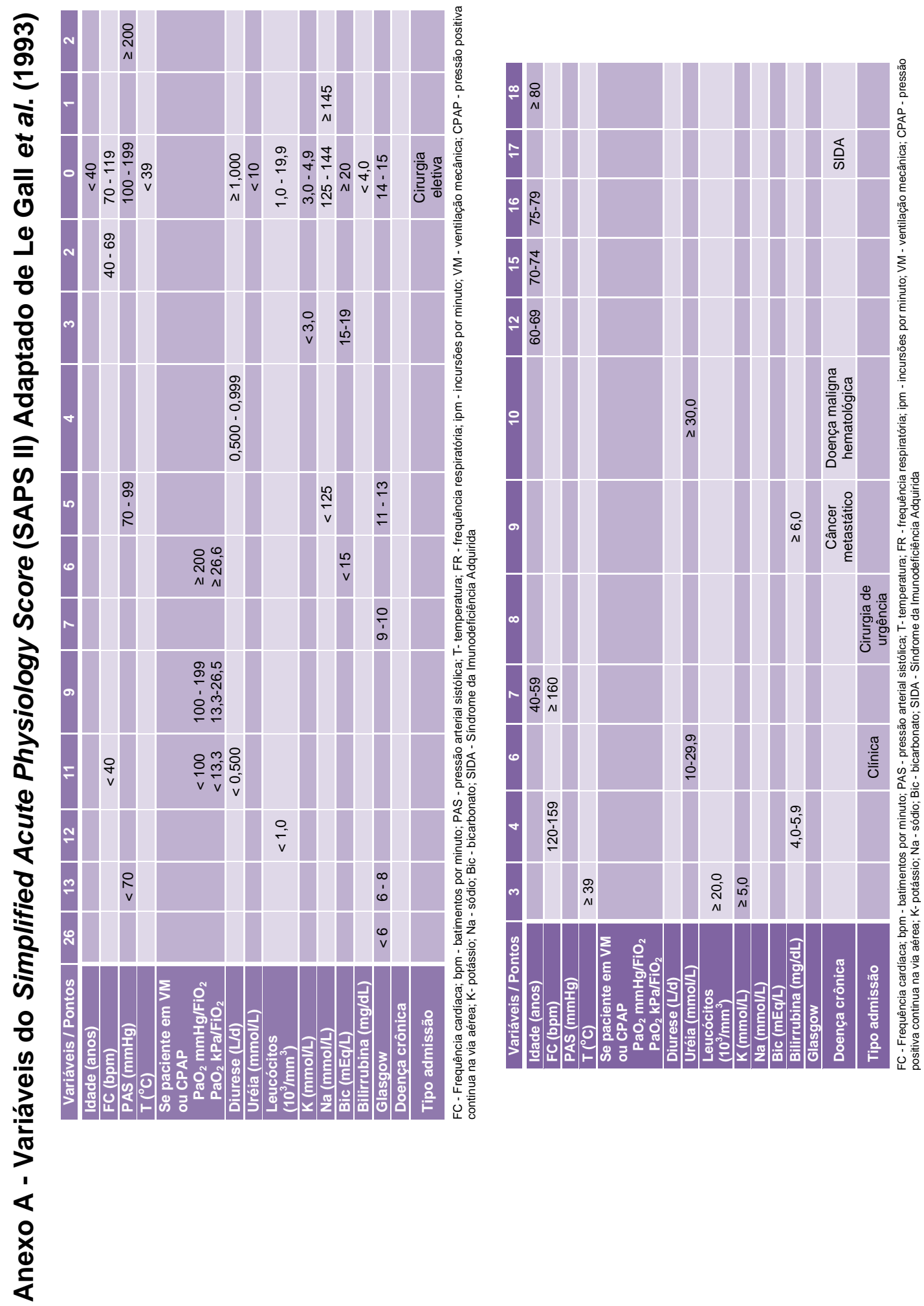

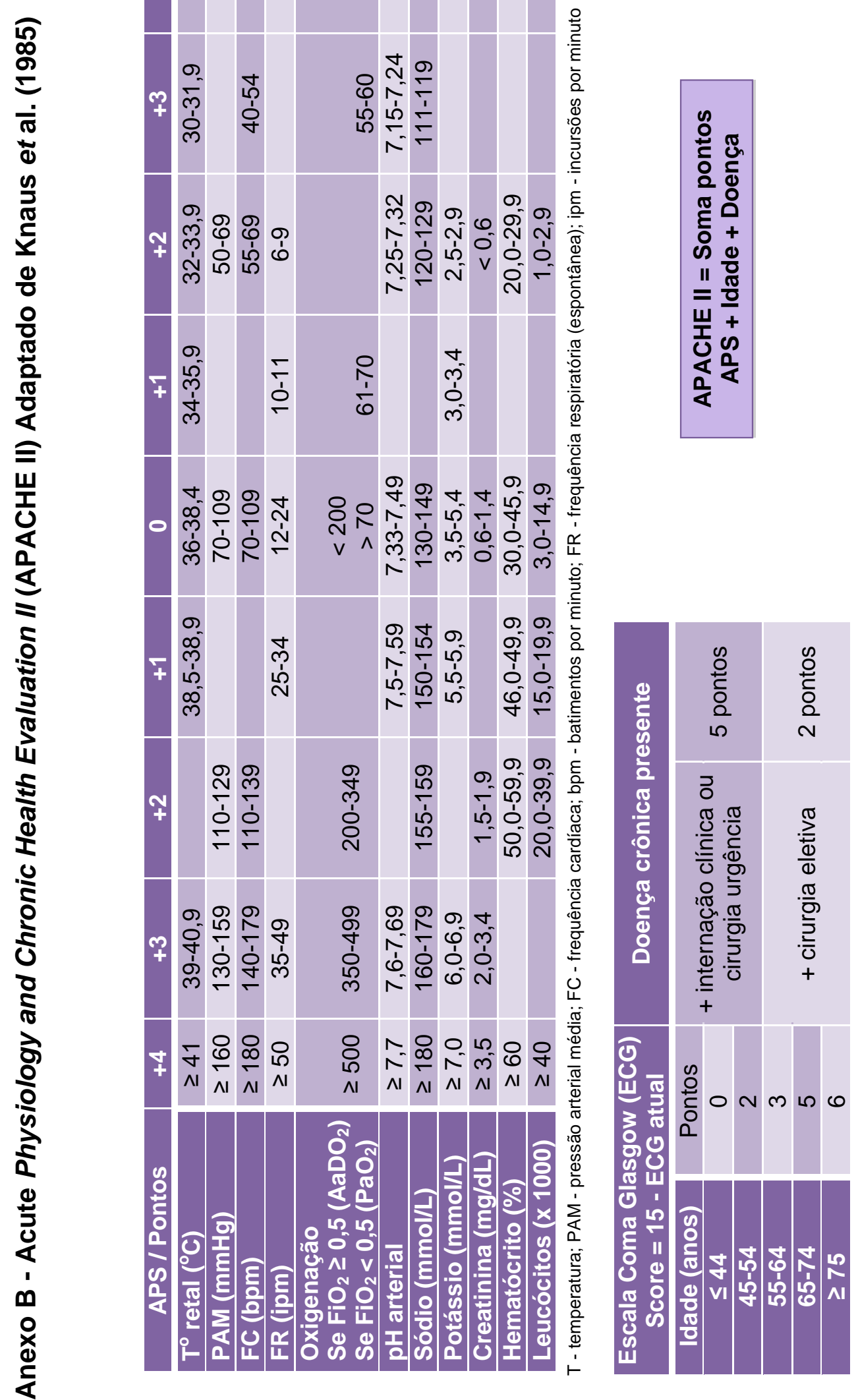


\section{Anexo C - Variáveis do Pediatric Risk of Mortality (PRISM) Adaptado de Pollack et al. (1988)}

\begin{tabular}{|c|c|c|c|}
\hline Variáveis & \multicolumn{2}{|c|}{ Variação de acordo com a idade } & Pontos \\
\hline PA sistólica $(\mathrm{mmHg})$ & $\begin{array}{c}\text { Lactente } \\
130-160 \\
55-65 \\
>160 \\
40-54 \\
<40 \\
\end{array}$ & $\begin{array}{c}\text { Crianças } \\
150-200 \\
65-75 \\
>200 \\
50-64 \\
<50 \\
\end{array}$ & $\begin{array}{l}2 \\
2 \\
6 \\
6 \\
7 \\
\end{array}$ \\
\hline PA diastólica $(\mathrm{mmHg})$ & \multicolumn{2}{|c|}{ Todas as idades $>110$} & 6 \\
\hline Frequência cardíaca (bpm) & $\begin{array}{l}>160 \\
<90\end{array}$ & $\begin{array}{l}>150 \\
<80\end{array}$ & $\begin{array}{l}4 \\
4\end{array}$ \\
\hline $\begin{array}{l}\text { Frequência respiratória } \\
\text { (rpm) }\end{array}$ & $\begin{array}{c}61-90 \\
>90 \\
\text { apneia }\end{array}$ & $\begin{array}{c}51-90 \\
>90 \\
\text { apneia }\end{array}$ & $\begin{array}{l}1 \\
5 \\
5 \\
\end{array}$ \\
\hline $\mathrm{PaO}_{2} / \mathrm{FiO}_{2}{ }^{\mathrm{a}}$ & \multicolumn{2}{|c|}{$\begin{array}{c}\text { Todas as idades } \\
200-300 \\
<200\end{array}$} & $\begin{array}{l}2 \\
3\end{array}$ \\
\hline $\mathrm{PaCO}_{2}(\mathrm{mmHg})^{\mathrm{b}}$ & \multicolumn{2}{|c|}{$\begin{array}{c}\text { Todas as idades } \\
51-65 \\
>65 \\
\end{array}$} & $\begin{array}{l}1 \\
5 \\
\end{array}$ \\
\hline EC Glasgow ${ }^{c}$ & \multicolumn{2}{|c|}{$\begin{array}{c}\text { Todas as idades } \\
<8\end{array}$} & 6 \\
\hline Reações pupilares & \multicolumn{2}{|c|}{$\begin{array}{c}\text { Todas as idades } \\
\text { Anisocóricas ou dilatadas } \\
\text { Fixas e dilatadas }\end{array}$} & $\begin{array}{c}4 \\
10\end{array}$ \\
\hline TP / TTPA & \multicolumn{2}{|c|}{$\begin{array}{l}\text { Todas as idades } \\
>1,5 \times \text { controle }\end{array}$} & 2 \\
\hline Bilirrubina total $(\mathrm{mg} / \mathrm{dL})$ & \multicolumn{2}{|c|}{$\begin{array}{c}\text { Maiores que } 1 \text { mês } \\
>3,5\end{array}$} & 6 \\
\hline Potássio (mg/dL) & \multicolumn{2}{|c|}{$\begin{array}{c}\text { Todas as idades } \\
3,0-3,5 \\
6,5-7,5 \\
<3,0 \\
>7,5\end{array}$} & $\begin{array}{l}1 \\
1 \\
5 \\
5\end{array}$ \\
\hline Cálcio (mg/dL) & \multicolumn{2}{|c|}{$\begin{array}{c}\text { Todas as idades } \\
7,0-8,0 \\
12-15 \\
<7,0 \\
>15\end{array}$} & $\begin{array}{l}2 \\
2 \\
6 \\
6 \\
\end{array}$ \\
\hline Glicemia (mg/dL) & \multicolumn{2}{|c|}{$\begin{array}{c}\text { Todas as idades } \\
40-60 \\
250-400 \\
<40 \\
>400 \\
\end{array}$} & $\begin{array}{l}4 \\
4 \\
8 \\
8 \\
\end{array}$ \\
\hline 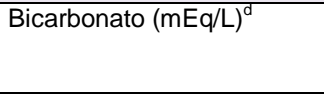 & \multicolumn{2}{|c|}{$\begin{array}{c}\text { Todas as idades } \\
<16 \\
>32 \\
\end{array}$} & $\begin{array}{l}3 \\
3\end{array}$ \\
\hline
\end{tabular}

a. Não deve ser realizado em pacientes com shunt intracardíaco ou insuficiência respiratória crônica; existe necessidade de amostra arterial.

b. Pode ser realizado com amostra de sangue capilar.

c. Não pode ser realizado em pacientes com sedação, paralisia, anestesia ou disfunção neurológica crônica.

d. Pode-se utilizar os valores medidos. 


\section{Anexo D - Variáveis do Pediatric Index of Mortality 2 (PIM2) Adaptado de Slater et al. (2003)}

O PIM2 é calculado baseado nas informações obtidas no momento da admissão na UTIP, durante a primeira hora de internação.

1. Pressão arterial sistólica (PAS), $\mathrm{mmHg}$ (se desconhecida $=120$ )

2. Resposta pupilar à luz (ambas $>3 \mathrm{~mm}$ e fixas $=1$, outra ou desconhecida $=0$ )

3. $\mathrm{PaO}_{2}, \mathrm{mmHg}$ (se desconhecido $=0$ ) e $\mathrm{FiO}_{2}$ no momento da coleta da $\mathrm{PaO} 2$ se oferta de oxigênio via tubo endotraqueal ou capacete (se desconhecido $=0$ )

4. Excesso de base arterial ou capilar, $\mathrm{mmol} / \mathrm{L}$ (se desconhecido $=0$ )

5. Ventilação mecânica na primeira hora da internação na UTI $(S I M=1, N A ̃ O=0)$

6. Admissão na UTI após cirurgia eletiva ou após procedimento eletivo, por exemplo, passagem de cateter central ou avaliação da ventilação domiciliar (NÃO $=0, \operatorname{SIM}=1$ )

7. A principal razão para a admissão na UTI é após uma cirurgia ou procedimento (NÃO $=0, S I M$ $=1$ )

8. Admissão após cirurgia com circulação extracorpórea $(\operatorname{SIM}=1, N A ̃ O=0)$

9. Patologia de alto risco $(\operatorname{SIM}=1, N \tilde{A} O=0)$ :

[0] Nenhuma

[1] Parada cardíaca antes da admissão na UCI

[2] Imunodeficiência combinada severa

[3] Leucemia/Linfoma após 1a indução

[4] Hemorragia Cerebral espontânea

[5] Cardiomiopatia ou miocardite

[6] Síndrome do Ventrículo esquerdo hipoplásico

[7] Infecção pelo HIV

[8] Insuficiência hepática, quando for a razão para admissão na UCI

[9] Desordens neurodegenerativas

10. Patologias de baixo risco $(\operatorname{SIM}=1, N A \tilde{O}=0)$ :

[0] Nenhuma

[1] Asma é a principal razão para admissão na UCI

[2] Bronquiolite é a principal razão para admissão na UCI

[3] Crupe é a principal razão para admissão na UCI

[4] Apneia obstrutiva é a principal razão para admissão na UCI

[5] Cetoacidose diabética é a principal razão para a admissão na UCI

1. Considerar 0 se PCR, 30 se choque e não for possível medi-la e 120 se desconhecida.

2. Reações pupilares à luz são usadas como um índice da função cerebral. Não considerar um achado anormal se a alteração é devido a drogas, toxinas ou lesão ocular local.

3. A ventilação mecânica inclui máscara nasal, CPAP (pressão positiva nas vias aéreas) ou BIPAP (pressão positiva nas vias aéreas em dois níveis de pressão) ou ventilação com pressão negativa.

4. Admissão eletiva. Incluir admissão após cirurgia eletiva ou para um procedimento eletivo (por exemplo, inserção de cateter central), monitorização eletiva ou revisão de ventilação mecânica domiciliar. Uma admissão na UTI é considerada eletiva se puder ser adiada por mais de 6 horas sem efeito adverso.

5. A recuperação de cirurgia ou procedimento inclui um procedimento radiológico ou cateterismo cardíaco. Não incluir pacientes internados a partir do centro cirúrgico onde recuperação da cirurgia não é a principal razão para admissão na UTI (por exemplo, um paciente com traumatismo crânio-encefálico (TCE) que é admitido após a inserção de um monitor pressão intracraniana; neste caso o principal motivo de internação na UTI é o TCE).

6. Bypass cardíaco. Estes doentes também devem ser classificados como recuperação da cirurgia. 
7. A parada cardiorrespiratória (PCR) anterior à admissão na UTI inclui aquelas ocorridas tanto no ambiente intra como extra-hospitalar. Requer ausência de pulso documentada ou a necessidade de compressão cardíaca externa. Não incluir pacientes com história prévia de PCR.

8. A hemorragia cerebral deve ser espontânea (isto é, por causa de aneurisma ou malformação arteriovenosa). Não inclua hemorragia cerebral intracraniana traumática ou hemorragia que não é intracerebral (por exemplo, hematoma subdural)

9. Síndrome de hipoplasia do coração esquerdo. Incluir pacientes de qualquer idade, mas apenas os casos em que um procedimento de Norwood ou equivalente é ou foi requerido no período neonatal para sustentar a vida.

10. A insuficiência hepática aguda ou crônica deve ser a razão principal para admissão na UTI. Incluir pacientes internados por recuperação de transplante hepático por insuficiência hepática aguda ou crônica.

11. Doença neurodegenerativa. Necessita de uma história de perda progressiva do DNPM (mesmo sem diagnóstico de condição específica), ou um diagnóstico em que a perda é inevitável.

12. Bronquiolite. Incluir as crianças que apresentem insuficiência respiratória ou apneia central e o diagnóstico clínico é bronquiolite.

13. Apneia obstrutiva do sono. Incluir pacientes internados após adenoidectomia e/ou amigdalectomia nos quais a apneia obstrutiva do sono é a principal razão para a internação em UTI (e também classificar como recuperação cirúrgica). 


\section{Anexo E - Variáveis do Pediatric Risk of Mortality IV (PRISM IV) Adaptado de Pollack et al. (2015)}

\begin{tabular}{|c|c|c|c|c|c|c|}
\hline \multicolumn{3}{|c|}{ Sinais vitais, cardiovasculares e neurológicos } & \multicolumn{4}{|l|}{ Testes bioquímicos } \\
\hline PA sistólica (mmHg) & Escore $=3$ & Escore $=7$ & Glicose & \multirow{2}{*}{\multicolumn{3}{|c|}{$\begin{array}{c}\text { Escore }=2 \\
>200 \mathrm{mg} / \mathrm{dl} \text { ou }>11 \mathrm{mmol} / \mathrm{L}\end{array}$}} \\
\hline Neonatal $^{\mathrm{a}}$ & $40-55$ & $<40$ & Todas as idades & & & \\
\hline Lactente & $40-65$ & $<45$ & & & & \\
\hline Criança & $55-75$ & $<55$ & & & & \\
\hline Adolescente & $65-85$ & $<65$ & & & & \\
\hline $\begin{array}{l}\text { Temperatura (todas as } \\
\text { Idades) }^{b}\end{array}$ & \multicolumn{2}{|c|}{ Escore $=3$} & $\begin{array}{l}\text { Potássio (mEq/L) } \\
\text { Todas as idades }\end{array}$ & \multicolumn{3}{|c|}{$\begin{array}{c}\text { Escore }=3 \\
>6,9\end{array}$} \\
\hline Status neurológico ${ }^{c}$ & \multicolumn{2}{|c|}{$\begin{array}{c}<33 \text { ou }>40^{\circ} \mathrm{C} \\
\text { Escore }=5\end{array}$} & Ureia $(\mathrm{mg} / \mathrm{dl})$ & \\
\hline Todas as idades & \multicolumn{2}{|c|}{ Estupor/Coma (Glasgow < 8) } & Neonatal & \multicolumn{3}{|c|}{$\begin{array}{l}>25,5 \\
>31,93\end{array}$} \\
\hline Frequência cardíaca $^{\alpha}$ & & & Outras idades & & & \\
\hline (bpm) & Escore $=3$ & Escore $=4$ & Creatinina (mg/dl) & \\
\hline Neonatal & $215-225$ & $>225$ & Neonatal & \multicolumn{3}{|c|}{$>0,85$} \\
\hline Lactente & $215-225$ & $>225$ & Lactente & \multicolumn{3}{|c|}{$>0,9$} \\
\hline Criança & $185-205$ & $>205$ & Criança & \multicolumn{3}{|c|}{$>0,9$} \\
\hline Adolescente & $145-155$ & $>155$ & \multirow[t]{2}{*}{ Adolescente } & \multicolumn{3}{|c|}{$>1,3$} \\
\hline $\begin{array}{l}\text { Reflexo pupilar (todas } \\
\text { as idades) }\end{array}$ & $\begin{array}{l}\text { Escore }=7 \\
\text { fixa unilateral }\end{array}$ & $\begin{array}{l}\text { Escore }=11 \\
\text { fixa bilateral }\end{array}$ & & & & \\
\hline \multicolumn{3}{|l|}{ Ácido-básico, gasometria ${ }^{\dagger}$} & \multicolumn{4}{|l|}{ Testes hematológicos } \\
\hline $\begin{array}{l}\text { Acidose }\left(\mathrm{pH} \text { ou } \mathrm{CO}_{2 \text { total }}\right) \\
\mathrm{pH} \\
\mathrm{CO}_{2}\end{array}$ & $\begin{array}{c}\text { Escore }=2 \\
7,0-7,28 \\
5-16,9\end{array}$ & $\begin{array}{c}\text { Escore }=6 \\
<7,0 \\
<5\end{array}$ & $\begin{array}{l}\text { Leucócitos (céls } / \mathrm{mm}^{3} \text { ) } \\
\text { Todas as idades }\end{array}$ & \multicolumn{3}{|c|}{$\begin{array}{c}\text { Escore }=4 \\
<3.000\end{array}$} \\
\hline $\begin{array}{l}\text { pH } \\
\text { Todas as idades }\end{array}$ & $\begin{array}{l}\text { Escore }=2 \\
7,48-7,55\end{array}$ & $\begin{array}{c}\text { Escore }=3 \\
\quad>7,55\end{array}$ & $\begin{array}{l}\text { Plaquetas }\left(\mathbf{x} 10^{3} \text { céls } / \mathbf{m m}^{3}\right) \\
\text { Todas as idades }\end{array}$ & $\begin{array}{l}\text { Escore }=2 \\
100-200\end{array}$ & $\begin{array}{c}\text { Escore }=4 \\
50-99\end{array}$ & $\begin{array}{c}\text { Escore }=5 \\
<50\end{array}$ \\
\hline $\begin{array}{l}\mathrm{PCO}_{2}(\mathbf{m m H g}) \\
\text { Todas as idades }\end{array}$ & $\begin{array}{c}\text { Escore }=1 \\
50-75\end{array}$ & $\begin{array}{c}\text { Escore }=3 \\
>75\end{array}$ & $\begin{array}{l}\text { TP ou TTPa (seg) } \\
\text { Neonatal } \\
\text { Outras idades }\end{array}$ & $\begin{array}{l}\text { TF } \\
\text { TF }\end{array}$ & $\begin{aligned} & \text { Escore }=3 \\
> & 22 \text { ou TTPa } \\
> & 22 \text { ou TTPa }\end{aligned}$ & $\begin{array}{l}>5 \\
>57\end{array}$ \\
\hline $\begin{array}{l}\mathrm{CO}_{2} \text { total } \\
\text { Todas as idades }\end{array}$ & \multicolumn{2}{|c|}{$\begin{array}{c}\text { Escore }=4 \\
>34\end{array}$} & & & & \\
\hline $\mathrm{PaO}_{2}(\mathrm{mmHg})^{\mathrm{g}}$ & $\begin{array}{l}\text { Escore }=3 \\
42-49\end{array}$ & $\begin{array}{c}\text { Escore }=6 \\
<42\end{array}$ & & & & \\
\hline
\end{tabular}

a. Neonatal: 0 - 1 mês; Lactente $\geq 1$ mês - 12 meses; Criança $\geq 12$ meses - 144 meses; Adolescente: > 144 meses.

b. Temperatura pode ser oral, retal, sanguínea ou axilar.

c. Status neurológico inclui somente pacientes com doença aguda do SNC, conhecida ou suspeita. Não usar se $>2$ horas de sedação, paralisia ou anestesia. Se está em uso de sedação e/ou paralisia contínua, usar o período sem sedação, paralisia ou anestesia próximo à admissão na UTI. Estupor/coma é definido como Glasgow < 8 ou usando outra escala de status mental.

d. Não usar o valor da frequência cardíaca durante o choro ou agitação iatrogênica.

e. Pupilas não reativas devem ser > 3mm; não usar esse critério após dilatação iatrogênica.

f. Distúrbio acido-base: usar bicarbonato calculado apenas se $\mathrm{CO}_{2}$ total não é medido rotineiramente. $\mathrm{pH}$ e $\mathrm{PCO}_{2}$ podem ser medidos de amostra arterial, capilar ou venosa.

g. $\mathrm{PaO}_{2}$ somente medida arterial.

Usar apenas a primeira admissão na UTI durante a hospitalização.

Alta ou óbito se refere a alta hospitalar e não a alta da UTI. 


\section{Anexo F - Pediatric Risk of Mortality IV (PRISM IV) para pacientes submetidos à intervenção cardíaca Adaptado de Pollack et al. (2015)}

\begin{tabular}{|llll|}
\hline Idade à admissão & $\begin{array}{l}\text { Dias de UTI antes da } \\
\text { intervenção cardíaca }\end{array}$ & Intervenção & $\begin{array}{l}\text { Coleta do PRISM } \\
\text { IV }\end{array}$ \\
\hline < 24h & $<12$ horas & Cirurgia cardíaca ou cateterismo & Admissão \\
& 12horas a 10 dias & Cirurgia cardíaca ou cateterismo & Pós-intervenção \\
\hline 24h a $\mathbf{1 0}$ dias & 0 a 10 dias & Cirurgia cardíaca ou cateterismo & Pós-intervenção \\
& $>10$ dias & Cirurgia cardíaca ou cateterismo & Admissão \\
\hline $\mathbf{1 1}$ a $\mathbf{3 0}$ dias & $<48$ horas & Cirurgia cardíaca ou cateterismo & Pós-intervenção \\
& $>48$ horas & Cirurgia cardíaca ou cateterismo & Admissão \\
\hline $\mathbf{3 1}$ a $\mathbf{9 0}$ dias & $<48$ horas & Cirurgia cardíaca & Pós-intervenção \\
& $<48$ horas & Cateterismo & Admissão \\
& $>48$ horas & Cirurgia cardíaca ou cateterismo & Admissão \\
\hline $\mathbf{9 0}$ dias & todos & Cirurgia cardíaca ou cateterismo & Admissão \\
\hline
\end{tabular}




\section{Anexo G - Variáveis do Pediatric Index Of Mortality 3 (PIM3) Adaptado de Straney et al. (2013)}

1. Pressão arterial sistólica (PAS), $\mathrm{mmHg}$ (se desconhecida $=120)^{\mathrm{a}}$

2. Reação pupilar à luz ( $>3 \mathrm{~mm}$ e ambas fixas $=1$; outra ou desconhecida $=0)^{\mathrm{b}}$

3. $\left(\left[\mathrm{FiO}_{2} \times 100\right] / \mathrm{PaO}_{2}\right) \cdot \mathrm{PaO}_{2} \mathrm{mmHg}, \mathrm{FiO}_{2}$ no momento da $\mathrm{PaO}_{2}$ se oxigênio via tubo endotraqueal ou capacete $\left(\mathrm{FiO}_{2}\right.$ ou $\mathrm{PaO}_{2}$ desconhecida, $\left.\left(\left[\mathrm{FiO}_{2} \times 100\right] / \mathrm{PaO}_{2}\right)=0,23\right)$

4. Base excesso em sangue arterial ou capilar, $\mathrm{mmol} / \mathrm{L}$ (se desconhecido $=0$ )

5. Ventilação mecânica em qualquer momento na primeira hora na UTI (não= $0 ; \operatorname{sim}=1)^{c}$

6. Admissão eletiva na UTI ( $n a ̃ o=0 ; \operatorname{sim}=1)^{d}$

7. Recuperação cirúrgica ou de um procedimento é a principal razão de admissão na UTI [0] Não

[1] Sim, recuperação de um procedimento com bypass cardíaco

[2] Sim, recuperação de um procedimento sem bypass cardíaco

[3] Sim, recuperação de um procedimento não cardíaco

8. Diagnóstico de baixo risco. Colocar o número entre os colchetes. Se dúvida considerar $=0$ [0] Nenhum

[1] Asma é a principal razão para admissão na UTI

[2] Bronquiolite é a principal razão para admissão na UTI ${ }^{f}$

[3] Crupe é a principal razão para admissão na UTI

[4] Apneia obstrutiva do sono é a principal razão para admissão na UTI ${ }^{g}$

[5] Cetoacidose diabética é a principal razão para admissão na UTI

[6] Convulsão é a principal razão para admissão na UTI ${ }^{h}$

9. Diagnóstico de alto risco. Colocar o número entre os colchetes. Se dúvida considerar $=0$

[0] Nenhum

[1] Hemorragia cerebral espontânea

[2] Cardiomiopatia ou miocardite

[3] Síndrome do coração esquerdo hipoplásico

[4] Doença neurodegenerativa ${ }^{k}$

[5] Enterocolite necrotizante é a principal razão para admissão na UTI

10. Diagnóstico de muito-alto risco. Colocar o número entre os colchetes. Se dúvida considerar = 0

[0] Nenhum

[1] PCR precedendo admissão na UTI'

[2] Imunodeficiência combinada grave

[3] Leucemia ou linfoma após primeira indução ${ }^{m}$

[4] Receptor de transplante de medula óssea

[5] Insuficiência hepática é a principal razão para admissão na UTI ${ }^{\text {n}}$

a. Considerar $\mathrm{PAS}=0$ se paciente em $\mathrm{PCR}$; considerar $\mathrm{PAS}=30$ se paciente está chocado e a PAS é muito baixa e não pode ser mensurada.

b. Reações pupilares à luz são usadas como indicador de função cerebral. Não considerar como achados anormais se são devido a drogas, toxinas ou injúria ocular.

c. Ventilação mecânica inclui ventilação invasiva, CPAP por máscara ou prong nasal, ou BIPAP ou ventilação com pressão negativa.

d. Admissão eletiva. Inclui admissão (planejada ou previsível) após cirurgia eletiva ou admissão após procedimento eletivo (p.ex., passagem de cateter venoso central), ou monitorização eletiva ou revisão de ventilação domiciliar. Uma admissão na UTI ou cirurgia é considerada eletiva se puder ser postergada por mais de 6 horas sem efeitos adversos. 
e. Recuperação de cirurgia ou procedimento (inclui procedimento radiológico ou cateterização cardíaca). Não inclui pacientes admitidos do centro cirúrgico após recuperação de cirurgia que não é a principal razão de admissão na UTI (p.ex., paciente com TCE que é admitido após inserção de cateter para monitorização de pressão intracraniana; neste caso a principal razão de admissão é o TCE).

f. Bronquiolite. Inclui crianças que apresentam desconforto respiratório ou apneia central cujo diagnóstico clínico é bronquiolite.

g. Apneia obstrutiva do sono. Inclui pacientes admitidos após adenoidectomia e/ou amigdalectomia nos quais apneia obstrutiva do sono é a principal razão de admissão na UTI (e vem para recuperar da cirurgia).

h. Convulsões. Inclui pacientes que necessitaram de internação primariamente por status epilético, epilepsia, convulsão febril, ou outras síndromes epiléticas cuja admissão é necessária para controle das convulsões ou para recuperar dos efeitos das convulsões ou tratamento.

i. Hemorragia cerebral deve ser espontânea (isto é, devido a aneurisma ou malformação AV). Não inclui hemorragia cerebral traumática ou hemorragia intracraniana que não é intracerebral (p.ex., hemorragia subdural).

j. Síndrome do ventrículo esquerdo hipoplásico. Em qualquer idade, mas inclui somente casos que necessitaram de Norwood ou equivalente no período neonatal para sobrevida.

k. Doença neurodegenerativa. Necessita de uma história de perda progressiva do DNPM (mesmo sem diagnóstico de condição específica), ou um diagnóstico em que a perda é inevitável.

I. PCR precedendo admissão na UTI inclui tanto PCR intra-hospitalar como extrahospitalar. Necessita documentação de ausência de pulso ou compressão cardíaca externa. Não inclui história de PCR.

m. Leucemia ou linfoma. Inclui somente casos em que a admissão está relacionada a leucemia ou linfoma ou ao tratamento dessas condições.

n. Insuficiência hepática, aguda ou crônica. Deve ser a principal razão para admissão na UTI. Não inclui pacientes admitidos para transplante hepático eletivo. 
Anexo H - Planilha Para coleta dos dados da população

\begin{tabular}{|c|c|c|c|c|c|c|c|c|c|c|c|}
\hline $\begin{array}{c}\text { REGISTRO } \\
\text { HOSPITALAR }\end{array}$ & $\begin{array}{l}\text { GÉNERO } \\
\text { (feminino ou } \\
\text { mascullinoo) }\end{array}$ & $\begin{array}{l}\text { IDADE } \\
\text { (mases) }\end{array}$ & 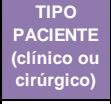 & 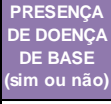 & \begin{tabular}{|l} 
MOTIVO DA \\
INTTRACA \\
NA UTI
\end{tabular} & 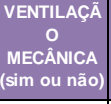 & $\begin{array}{c}\text { DROGA } \\
\text { VASOAATIVA } \\
\text { (sim ou nâa) }\end{array}$ & $\begin{array}{l}\text { DAAS DE } \\
\text { INTERNACÁ } \\
0\end{array}$ & $\begin{array}{l}\text { PRISN } \\
\text { pontos }\end{array}$ & $\operatorname{PIM} 2$ (\%) & $\begin{array}{c}\text { ósito } \\
\text { (sim ou } \\
\text { não) }\end{array}$ \\
\hline & & & & & & & & & & & \\
\hline & & & & & & & & & & & \\
\hline & & & & & & & & & & & \\
\hline & & & & & & & & & & & \\
\hline & & & & & & & & & & & \\
\hline & & & & & & & & & & & \\
\hline & & & & & & & & & & & \\
\hline & & & & & & & & & & & \\
\hline & & & & & & & & & & & \\
\hline & & & & & & & & & & & \\
\hline & & & & & & & & & & & \\
\hline & & & & & & & & & & & \\
\hline & & & & & & & & & & & \\
\hline & & & & & & & & & & & \\
\hline & & & & & & & & & & & \\
\hline & & & & & & & & & & & \\
\hline & & & & & & & & & & & \\
\hline & & & & & & & & & & & \\
\hline & & & & & & & & & & & \\
\hline & & & & & & & & & & & \\
\hline & & & & & & & & & & & \\
\hline & & & & & & & & & & & \\
\hline & & & & & & & & & & & \\
\hline & & & & & & & & & & & \\
\hline & & & & & & & & & & & \\
\hline & & & & & & & & & & & \\
\hline & & & & & & & & & & & \\
\hline & & & & & & & & & & & \\
\hline
\end{tabular}




\section{Anexo I - Aprovação do estudo pela Comissão de Ética para Análise de Projetos de Pesquisa (CAPPesq)}

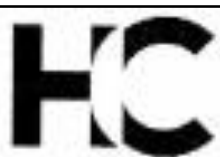

\section{APROVAÇĀO}

A Comissảo de Ética para Análise de Projetos de Pesquisa - CAPPesq da Diretaria Clínica do Hospital das Clinicas e da Faculdade de Medicina da Universidade de São Paulo, em sessăo de 22.10.08, APROVOU \& Protocalo de Pesquisa $n^{\circ}$ 0912/08 , intitulado: - Avalioção do prognóstico com a utilizaçāo de dois escores de mortalidade em terapia intensiva pediátrica de nível de atendimento ferciário*, apresentado pelo Departamento de Pediatria.

Cabe ao pesquisodor elaborar e apresentar a CAPPesq. os relatónios parciais e final sobre a pesquiso |Resoluçāo do Conselho Nacional de Saúde $n^{\circ} 196$, de 10,10.1996, inciso IX. 2, letra "c"].

Pesquisador(a) Responsável: Dr. Artur Figuelredo Delgado

Pesquisodor(a) Executante : Graziela de Araújo Costo

CAPPesc, 22 de outubro de 2008.

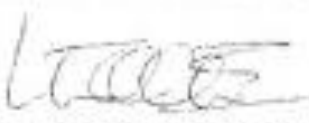

PROF. DR. CLAUDIO IEONE

Vice- Presidente da Comlssão de Élica para Análise de Projetos de Pesquisa 


\section{REFERÊNCIAS}


Batista CC, Gattass CA, Calheiros TP, Moura RB. Avaliação prognóstica individual na UTI: é possível diferenciar insistência terapêutica de obstinação terapêutica? Rev Bras Ter Intensiva. 2009; 21:247-54.

Bekhit OSM, Algameel AA, Eldash HH. Application of pediatric index of mortality version 2: score in pediatric intensive care unit in an African developing country. Pan African Med J. 2014; 17:185.

Canonero I, Figueroa A, Cacciamano A, Olivier E, Cuestas E. Validation of PRISM e PIM2 scores of mortality in a pediatric intensive care unit in Cordoba. Arch Argent Pediatr. 2010; 108:427-33.

Costa GA, Delgado AF, Ferraro A, Okay TS. Application of the Pediatric Risk of Mortality Score (PRISM) score and determination of mortality risk factors in a tertiary pediatric intensive care unit. Clinics. 2010; 65(11):1087-92.

Donabedian A. Evaluating the quality of medical care. Milbank Mem Fund Q. 1966; 44:166-206.

Ebenezer K, Narasimhan M. Validation of Paediatric Index of Mortality Score 2 (PIM2) for prediction of mortality in a paediatric intensive care unit (PICU) in a tertiary care hospital in S. India. Pediatr Crit Care Med. 2011; 12(3 Suppl.):A78. 
El-Karaksy HM, El-Shabrawi MM, Mohsen NA, El-Koofy NM, El-Akel WA, Fahmy ME, Yassin NA. Study of predictive value of pediatric risk of mortality (PRISM) score in children with end stage liver disease and fulminant hepatic failure. Indian J Pediatr. 2011; 78(3):301-6.

El-Nawawy A. Evaluation of the outcome of patients admitted to the Pediatric Intensive Care Unit in Alexandria using the Pediatric Risk of Mortality (PRISM) Score. J Trop Pediatr. 2003; 49:109-14.

Espuñes SP, Cid JL, Galán CR, Villanueva AM, Torre AC, Comblor PM. Prognostic Indexes of Mortality in Pediatric Intensive Care Units. An Pediatr. $2007 ; 66(4): 345-50$.

Eulmesekian DP, Pérez A, Minces P, Ferrero H, Bimbi TF. Validación de dos modelos de predicción de mortalidad, PRISM y PIM2, en una Unidad de Cuidados Intensivos Pediátricos. Arch Argent Pediatr. 2006; 104:387-92.

Eulmesekian PG, Perez A, Minces PG, Ferrero H. Validation of pediatric index of mortality 2 (PIM2) in a single pediatric intensive care unit of Argentina. Ped Crit Care Med. 2007; 8(1):54-7.

Fernández A, López MA, Ratto M, Saligari L, Serrate S. A Validation of Pediatric Index of Mortality 2 (PIM2) in Argentina: a prospective, multicenter, observacional study. Arch Argent Pediatr. 2015; 113:221-8.

Fonseca JG, Ferreira AR. Application of the Pediatric Index of Mortality 2 in pediatric patients with complex chronic conditions. J Pediatr. 2014; 90:50611. 
Garcia P, Piva J, Korbi C, Camargo R, Lentz R, Dalcin T, Velozo KDS, Cabral DD, Branco RG, Tasker RC. PRISM, score performance after 20 years. Pediatr Crit Care Med. 2011; 12(3 Suppl.):A86-7.

Garcia PCR, Piva JP. Pediatric index of mortality 2 (PIM2) - A prognostic tool for developing countries: Easy, efficient, and free! Ped Crit Care Med. 2007; $8(1): 77-8$.

Glance LG, Osler T, Shinozaki T. Effect of varying the case mix on the standardized mortality ratio and W statistic: A simulation study. Chest. 2000; 117(4):1112-7.

Gustafson DH, Fryback D, Rose J. Decision: Theoretical methodology for severity index development. Madison, WI, Center for Health Systems Research and Analysis, University of Wisconsin, 1981.

Hanley JA, McNeil BJ. A method of comparing the areas under receiver operating characteristic curves derived from the same cases. Radiology. 1983; 148(3):839-43.

Hanley JA, McNeil BJ. The meaning and use of the area under a receiver operating characteristic (ROC) curve. Radiology. 1982; 143(1):29-36.

Hariharan S, Krishnamurthy K, Grannum D. Validation of Pediatric Index of Mortality 2 scoring system in a pediatric intensive care unit, Barbados. J Trop Pediatr. 2011; 57:7-13. 
Imamura T, Nakagawa S, Goldman RD, Fujiwara T. Validation of Pediatric Index of Mortality 2 (PIM2) in a single pediatric intensive care unit in Japan. Int Care Med. 2012; 38:649-54.

Knaus WA, Draper EA, Wagner DP, Zimmerman JE. APACHE II: A severity of disease classification system. Crit Care Med. 1985; 13:818-29.

Knaus WA, Zimmerman JE, Wagner DP, Draper EA, Lawrence DE. APACHE - acute physiology and chronic health evaluation: a physiologically based classification system. Crit Care Med. 1981; 9:591-7.

Le Gall J, Lemeshow S, Saulnier F. A new Simplified Acute Physiology Score (SAPS II) based on a European/North American Multicenter Study. JAMA. 1993; 270:2957-63.

Le Gall J, Loirat P, Alpervocitch A, Glaser P, Granthil C, Mathieu D, Mercier P, Thomas R, Villers D. A Simplified Acute Physiology Score for ICU patients. Crit Care Med. 1984; 12:975-7.

Lemeshow S, Hosmer DW, Jr. A review of goodness of fit statistics for use in the development of logistic regression models. Am J Epidemiol. 1982; 115(1): 92-106.

Leteurtre S, Leclerc F, Martinot A, Cremer R, Fourier C, Sadik A, Grandbastien B. Can generic scores (Pediatric Risk of Mortality and Pediatric Index of Mortality) replace specific scores in predicting the outcome of presumed meningococcal septic shock in children? Crit Care Med. 2001; 29(6): 1239-46. 
Lima Netto A, Muiz V, Zandonade E, Maciel E, Nichio Bortolozzo R, Ferreira Costa N, Limongi R. Performance of the Pediatric Index of Mortality 2 in a pediatric intensive care unit. Rev Bras Ter Intensiva. 2014; 26:44-50.

Lopez MPA, Fernández AR, Ratto, ME, Saligari L, Serrate AS, Ko IJ, Troster E, Schnitzler E, Viladar PIM, Latin american Group. Pediatric Index of Mortality 2 as a predictor of death risk in children admitted to pediatric intensive care units in Latin America: A prospective, multicenter study. J Crit Care. 2015; 30:1324-30.

Martha VF, Garcia PCR, Piva JP, Einloft PR, Bruno F, Rampon V. Comparação entre dois escores prognósticos (PRISM e PIM) em uma unidade de terapia intensiva pediátrica. J Pediatr. 2005; 81(3):259-64.

Mestrovic J, Kardum G, Polic B, Omazic A, Stricevic L, Sustic A. Applicability of the Australian and New Zealand pediatric intensive care registry diagnostic codes and paediatric index of mortality 2 scoring system in a Croatian paediatric intensive care unit. Eur J Pediatr. 2005; 164:783-4.

Netto AL, Muniz VM, Zandonade E, Bortolozzo RN, Costa NF, Limonge RSA. Peformance of Pediatric Index of Mortality 2 in a Brazilian pediatric intensive care. Pediatr Crit Care Med. 2011; 12(3 Suppl):A112.

Netto AL, Muniz VM, Zandonade E, Maciel ELN, Bortolozzo RN, Costa NF, Limongi $\mathrm{R}$ da $\mathrm{S}$. Performance of the Pediatric Index of Mortality 2 in a pediatric intensive care unit. Rev Bras Ter Intensiva. 2014; 26(1):44-50. 
Ozer EA, Kizilgunesker A, Sarioglu B, Haliciolgu O, Sutcuoglu S, Yaprak I. The Comparison of PRISM and PIM scoring systems for mortality risk in infantile intensive care. J Trop Ped. 2004; 50(6):334-8.

Pollack MM, Dean JM, Butler J, Holubkov R, Doctor A, Meert KL, Newth CJ, Berg RA, Moler F, Dalton H, Wessel DL, Berger J, Harrison RE, Carcillo JA, Shanley TP, Nicholson CE. The Ideal Time Interval for Critical Care Severityof-IIIness Assessment. Pediatr Crit Care Med. 2013; 14:448-53.

Pollack MM, Holubkov R, Funai T, Berger JT, Clark AE, Meert K, Berg TA, Carcillo J, Wessel DL, Moler F, Dalton H, Newth CJ, Shanley T, Harrison RE, Doctor A, Jenkins TL, Tamburro R, Deam JM, Eunice Kennedy Shirver National Institute of Child Health and Human Development Collaborative Pediatric Critical Care Research network. Simultaneous prediction of new morbidity, mortality, and survival without new morbidity from pediatric intensive care: a new paradigm for outcomes assessment. Crit Care Med. 2015; 43(8):1699-709.

Pollack MM, Holubkov R, Funai T, Dean JM, Berger JT, Wessel DL, Meert K, Berg RA, Newth CJ, Harrison RE, Carcillo J, Dalton H, Shanley T, Jenkins TL, Tamburro R, Eunice Kennedy Shirver National Institute of Child Health and Human Development Collaborative Pediatric Critical Care Research network. The Pediatric Risk of Mortality Score: Update 2015. Pediatr Crit Care Med. 2016; 17(1):2-9.

Pollack MM, Patel KM, Ruttimann UE. PRISM III: An update Pediatric Risk of Mortality score. Crit Care Med. 1996; 24 (5):743-52. 
Pollack MM, Ruttimann E, Getson PR. Pediatric risk of mortality (PRISM) score. Crit Care Med. 1988; 16(11):1110-6.

Pollack MM, Ruttimann UE, Getson PR. Accurate prediction of the outcome of pediatric intensive care. A new quantitative method. N Engl J Med. 1987; $316(3): 134-9$.

Pollack MM. Severity-of-illness Scoring Systems. In: Nichols DG (Eds.). Rogers' textbook of Pediatric Intensive Care. Philadelphia: Lippincott Williams \& Wilkins. $4^{\text {th }}$ ed. 2015. p.106-113.

Salamanti P, Talaee S, Eghbalkhah A, Chaman R, Mokhtari Z, Azarshahin M. Validation of Pediatric Index of Mortality 2 scoring system in a single pediatric intensive care unit in Iran. Iran J Pediatr. 2012; 22:481-6.

Sankar J, Singh A, Sankar MJ, Joghee S, Dweangan S, Dubey N. Pediatric index of mortality and PIM2 scores have good calibration in a large cohort of children from a developing country. Biomed Res Int. 2014; 2014:1-7.

Shann F, Pearson G, Slater A, Wilkinson K. Paediatric index of mortality a mortality prediction model for children in intensive care. Intens Care Med. $1997 ; 23: 201-7$

Shann F. Are we doing a good job: PRISM, PIM and all that. Intensive Care Med. 2002; 28(2):105-7.

Slater A, Shann F, Pearson G. PIM2: a revised version of the paediatric index of mortality. Int Care Med. 2003; 29:278-85. 
Slater A, Shann F. The suitablility of the pediatric index of mortality (PIM), PIM2, the pediatric risk of mortality (PRISM), and PRISM III for monitoring the quality of pediatric intensive care in Australia and New Zealand. Ped Crit Care Med. 2004; 5(5):447-54.

Strand K, Flaatten H. Severity scoring in the ICU: a review. Acta Anaesthesiol Scand. 2008; 52:467-78.

Straney L, Clements A, Parslow RC, Pearson G, Shann F, Alexander J, Slater A, ANZICS Paediatric Study Group and the Paediatric Intensive Care Audit Network. Paediatric Index of Mortality 3: An Updated Model for Predicting Mortality in Pediatric Intensive Care. Pediatr Crit Care Med. 2013; 14:673-81.

Taori RN, Lahiri KR, Tullu MS. Performance of PRISM (Pediatric Risk of Mortality) Score and PIM (Pediatric Index of Mortality) Score in a Tertiary Care Pediatric ICU. Indian J Pediatr. 2010; 77(3):267-71.

Teasdale G, Jennett B. Assessment of coma and impaired consciousness. A practical scale. Lancet. 1974; 2:81-4.

Thunkral A, Lodha R, Irshad M, Arora N. Perfomance of Pediatric Risk of Mortality (PRISM), Pediatric Index of Mortality (PIM) and PIM2 in a pediatric intensive care unit in a developing country. Ped Crit Care Med. 2006; 7(4):356-61.

Van Brakel MJM, Vught AJ, Gemke RJBJ. Pediatric risk of mortality (PRISM) score in meningococcal disease. Eur J Pediatr. 2000; 159:232-6. 
Waters M, Nightingale P. Scoring and outcome audit systems relevant to emergency medicine. Arch Emerg Med. 1990; 7:9-15.

Wheeler MM. APACHE: an evaluation. Crit Care Nurs Q. 2009; 32(1):46-8.

Wolfler A, Silvani P, Musicco M, Salvo I. Pediatric index of mortality 2 score in italy: a multicenter, prospective, observational study. Int Care Med. 2007; 33:1407-13.

Yeh TS, Pollack MM, Ruttimann UE, Holbrook PR, Fields AI. Validation of a physiologic stability index for use in critically ill infants and children. Pediatr Res. 1984; 18:445. 


\section{APÊNDICES}




\section{Apêndice A - Trabalho apresentado durante $\circ 7^{\text {th }}$ World Congress on Pediatric Intensive and Critical Care, 2014. Istambul, Turquia}

implementations of a complex inter-professional intervention in acute hospital settings to describe differences in approach and the relative impact on innovahospitals implementing the BedsidePEIVS innovation was performed Tw implementation team members completed a qualitative review of data obtain from audiotapes and notes of weekly meetings with each hospital team. The matic analysis identified common domains in implementation approaches. Thesc domains were validated with the site teams and grouped into the PHARIS frame work (evidence, facilitation, and context) for further analysis. Results: Data wa: synthesized from 109 hour-long meetings (22-34 per team). Three implementaton domains were identified along with seven domain -specific items; socially embeded process (front line cagagement, use of champions), organizational leve tation team characteristics) and fit of the innovation (customization, education) In the domains of social process and innovation fit we found that implementation items manifested across a continuum of influcnce from facilitator to barrier. Organization influences for change were primarily internally driven across al sites. The composition of implementation teams differed between sites as being either research or clinically situated. Conclusions: Future quantification of thes vation adoption is planned.

\section{1}

ESTABLISHING A PAEDIATRIC CARDIAC SURGICAL PROGRAM IN BENGHAZI, LIBYA

J. Evans'; 'Nurse Education, International Children's Heart Foundation, Mel. bourne, Australia

Background and aims: Until recently children in Libya had to travel to Tripoli or abroad to receive cardiac surgery. The Ministry of Health and Benghazi Medical Centre invited International Children's Heart Foundation (ICHF) to assi with the establishment of a paediatric cardiac surgical program in Benghazi.
A 1 year program commenced in October, 2013 with a small team of ICHP A taff residing in Benghazi to work alongside and train the Libyan staff. Aims:
To discuss the establishment of the 1 year program induding education aims To discuss the establishment of the 1 year program induding education aim retrospective review of ICHF education records, surgical and ICU database, and risk register was undertaken with approval from the institutional review board. Resulss: The first two months: 37 patients underwent 39 procedures with a mean RACHS of 2 , and survival to discharge of $97 \%$. Median age was 20 months and weight of $10 \mathrm{~kg} .13$ patients were extubatod in theatre, with the ramainder ventilated in ICU for a mean of 3.9 hours. Morbidity in ICU included bleedin $(16 \%)$, stridor $(11 \%)$, and arrhychmia (S\%). One pad infection, no patent had ventilator acquired pneumonia or central line associand tutorials, and demonstrated essential skills such as basic life support. Issuo encountered included security, intensivist training, access to radiology services, and obtaining some essential stock. Conclusions: Establishing a program such as this is a significant undertaking. It is important to review and monitor educational progress and patient outcomes.

912

NEURO CRITICAL CARE NURSING CURRICULUM IN A PEDIATRIC MEDICAL-SURGICAL ICU

J. Feinberg', J. Feinberg, E. Robertshaw'; 'Medical Surgicall Intensive Care Unit, Children's Hosp/Harvard Medical School, Boston, USA

Background and aims: A neurological critical care physician spocialist, Dr.Tasker, was hired with the objective of educating nurses and physicians in advance of initiating a new neurological critical care program. Education sessions were established to instruct the nurses in the medical -surgical ICU. Sessions
transitioned from physician led presentations to nurse led case studies. Aims: transitioned from physician led presentations to nurse led case studies. Aims: To increase nursing knowledge in the care of the complex neurological patien population. Methods: Initial education started with physician led lectures, which transitionad to nurse driven patient presentations faclitad by D.. Tasker. Each allowing thoughtful pauses to encourage critical thinking along with revicw of scans/treatment regiments. Diagnoses included. traumatic brain injury meningtis, metabolic disorder, and brain tumor, right parietal/temporal subdural hematoma and head bleed secondary to familial intrahepatic cholestasis II. Results A formalized nurse led monthly discussion of complex neurological patients has been achieved. The formal discussion includes, patient's initial presentation, first 24 hours symptoms and management, ongoing ICU care, treatment, and
follow up status of the patient. Discussions were supplemented with CT/MRI scans, medications and treatment regimes, along with discussion of what went well and what could we have done diffecently. Conclusions: Nurse led patient presentations led to the recognition of gaps in unit based nursing guidelines munication was accomplished once the need was recognized.

\section{3}

PERFORMANCE OF TWO SCORING SYSTEMS IN A TER TIARY PEDIATRIC INTENSIVE CARE UNIT IN A DEVELOP ING COUNTRY

GA.C. Zanatta', J.F. Ferranti', W.B. Carvalho', A.F. Delgado'; 'Pediatric Inten Clinicas da Faculdade de Medicina da Universidade de Sao Paulo, Sao Paulo, Brazi Background and aims: Technological advances in pediatric intensive care units
(PICU) resulted sophisticatod care for dildren. However, it has not always succeeded in improving quality of care which be assess using mortality scoring systems Two most usod are Pediatric Risk of Mortality (PRISM) and Podiatric Index of Mortality (PIM). There is no consensus about their usefulness and standardization,
especially in a tertiary PICU. Aims: We hypothoizod there might be difference in efficacy in the prediction of risk of death between two sores due to the sereity of these patients. Methods: Retrospective cohort study in a tertiary PICU tha receives highly complex diseases. Performance of PRISM and PIM2 was evaluated through standardized mortality ratio (SMR), discrimination and calibration. The IRB approval this study. Results: During one year 359 patients were included with 54 deaths $(15 \%)$. The mean admission diagnoses were clinical $(78 \%)$ an the major cause was respiratory $(37,3 \%)$. The SMR $(95 \% \mathrm{CI})$ for PIM2 was 1,1 Lemeshow goodness-of-fit test showed $\times 2=12,96(\mathrm{p}=0,11)$ for PRISM and $\times 2=13$, $(p=0,09)$ for PIM2. Discrimination assessed by ROC curves $(95 \%$ IC) showed an area under the curve of $0,76(0,69-0,83)$ for PRISM and $0,65(0,57-0,72)$ for PIM2, $\mathrm{p}=0,002$. Conclusions: Although both scores underestimated mortality using SMR, they had adequate calibration using Hosmer-Lemeshow test. For Ticu.

\section{4}

EFFECT OF MASSACHUSETTS GRADUATED DRIVER LICENSING SYSTEM ON ADOLESCENT MOTOR VEHICLE CRASHES

M. Flaherty' J. Garb' N. Miller', L. Koenigs'; 'Pediatrics, Baystate Children's Hospital, Springfield, USA

Background and aims: Motor vehicle crashes(MVCs) are the most common cause of death in the United States for adolescents. Since 1998. Massachusetts has implemented a Graduated Driver Licensing (GDL) system requiring teenagers to gain experience under conditions of low cash risk before gaining full privileges. Aims: To evaluate the impact of changes to strengthen Massachusetts' GDL law on MVCs in 16-18 year olds, and to assess whether these effects persist into young adulthood. Methods: Massachusetts MVC rates were analyzed for driver aged 16-24 years during two time periods: 2002-2006, before the GDL law was strengthened, and 2007 (tourth quarter)-2010, after implementation. Piecewise
regression was performed to test whether the rate of change in crash rates by quarter was different for the two time periods after controlling for age and se of the driver. Results: MVC rates for drivers aged 16-24 declined by $0.5 \%$ per quarter prior to implementation of changes to GDL in 2007, with an accelerate drop of $3.7 \%$ per quarter after 2007 , a difference of $3.5 \%(p<0.001)$. Results showed a significant difference in hour of crash and age group of driver. For those 16-18, the percentage of cashes occurring between $12.5 \mathrm{am}$ dropped from $7.2 \%$ before 2007 to $6.3 \%$ after 2007 (p<0.001. For 19-24-year olds there was a simiConclusions: Changes to the Massachuserts GDL law in $2007.2 \%$ after 2007. education, as well as to enact stricter penalties for violations have contributed to a significant decline in crash rates for Massachusetts youth. These effects persis into young adulthood.

915

SUPPORTING STAFF IN THE CARE OF DETERIORATING CHIDREN OUTSIDE OF PICU TO IMPROVE OUTCOMES AND EXPERIENCE - A PROGRESS REPORT

AND EXPERIENCE - A PROGRESS REPORT Birmingham, United Kingdom

Background and aims: High dependency care is provided on wards with no formal $\mathrm{HDU}$ area resulting in softe admissions to $\mathrm{FCU}$. The introduction of has enabled children to remain on familiar wards with support of PACE tean 


\section{Apêndice B - Carta do Editor}

\section{Letters to the Editor \\ Selecting the Best Mortality Risk Scoring Systems in a PICU: A Difficult Decision}

\section{To the Editor:}

The prognostic mortality scores are useful to assess the quality of care, compare the different services, scale professionals according to complexity, determine the prognosis, and estimate the risk of mortality $(1,2)$. Pediatric Risk of Mortality (PRISM) and Pediatric Index of Mortality (PIM) are commonly used in children. So far there is no consensus in the literature on which of these would be more usefu and practical, especially in tertiary PICU,

In a recent issue of Pediatric Critical Care Medicine, Sankar et al (3) performed a prospective observational study in a tertiary PICU in a developing country, with a high mortalit rate (33\%). There were 282 patients (one fourth were severely malnourished and $31 \%$ had any underlying chronic illness). The major reason for ICU admission and mortality was sepsis. The values of the PIM and PIM2 were recorded at 1 and 4 hours after admission. Both scores showed acceptable discrimination (receiver operating characteristic [ROC] curve: PIM, $1 \mathrm{hr}=0.70$ and $4 \mathrm{hr}=0.73 ;$ PIM $2,1 \mathrm{hr}=0.71$ and $4 \mathrm{hr}=$ 0.72 ) and good calibration. As considered by the authors, the discriminatory ability at both time points was just above 0.70 , lower than that reported from studies across the world probably because of the high mortality, differences in disease patterns, and possible influence of malnutrition. Despite a study in a single center, it was useful in this PICU and demonstrated that the PIM2 can also be used, including after the first hour, mainly in units where it is difficult to obtain data on the first hour of admission (3).

We performed a study in 359 critically ill children and adolescents in a tertiary PICU in a developing country (mortality rate $=15 \%$ ). Using data of the first hour of admission, we demonstrated that although PIM2 has a good calibration, it did not show an acceptable discrimination (ROC curve = 0.65 [95\% CI, 0.57-0.72]) (unpublished data). In an article that we published, PRISM had an acceptable discrimination (ROC curve $=0.76[95 \% \mathrm{Cl}, 0.69-0.83])$ and good calibration (1) in a population similar to that reported in the study by Sankar et al (3).

Although Sankar et al (3) had defined the use of PIM2 as appropriate for their population, it would be interesting to compare their findings with another score because the presence of confounding factors (i.e., small sample size of patients in the different subgroups) is a major source of bias in epidemiological studies. PRISM has proved suitable in other studies and perhaps scores that use more physiological variables may

Copyright 02013 by the Society of Critical Care Medicine and the World Federation of Pediatric Intensive and Critical Care Societies be more effective in tertiary PICUs, with higher rates of morbidity and mortality (1).

Castellanos-Ortega and Delgado-Rodríguez (4) and Leteurtre et al (5) demonstrated that PRISM had good discrimination in patients with meningococcal septic shock. Visser et al (2) studied the prognostic scores in more than 12,000 patients and demonstrated that the updated and patented PRISM III had better discrimination and PIM2 better calibration. PRISM (initial version) also had a good performance (3)

In conclusion, the use of prognostic mortality scores is essential for the assessment of quality of care in the PICU, and the definition of what score is more appropriate is a difficult decision. It should be based on data from the unit itself, influenced by the region/country to estimate mortality and best practices in the PICU.

The authors have disclosed that they do not have any potential conflicts of interest.

Graziela de A. C. Zanatta, MD, Werther B. Carvalho, PhD, Artur F Delgado, MD PhD, Children's Institute of Sao Paulo Urtur F. Delgado, MD Phity, Sao Paulo, Brazil

\section{REFERENCES}

Costa GA, Delgado AF, Ferraro A, et al: Application of the pediatric risk of mortality (PRISM) score and determination of mortaity risk 2010; 65:1087-1092

2. Visser IH, Hazelzet JA, Albers MJ, et al: Mortality prediction models for pediatric intensive care: Comparison of overall and subgroup specific pedatric intensive care: Comparison of overall and subgro 3. Sankar J, Chandel A, Dubey NK, et al: Do Interventions in an ICU Index the Chadictive Ability of Pediatric index of Mortaity and Pediatric Index of Mortality-2 Scores in
Care Med 2013;14:e70-e76

4. Castellanos-Ortega A, Delgado-Rodriguez M: Comparison of the performance of two general and three specific scoring systems 2B:2967-2973

5. Leteurtre S, Leclerc F, Martinot A, et al: Can generic scores (Pediatric Risk of Mortality and Pediatric Index of Mortality) replace specific shock in children? Crit Care Med 2001; 29:1239-1246.

DOI: $10.1097 /$ PCC. 0 b013e3182975ce5

\section{The authors reply:}

T $T$ e fully agree with Zanatta et al (1) that the choice of optimal score to be used in ICU setting is not known. As highlighted by them, the Pediatric Risk of Mortality (PRISM) score with its large number of physiological variables should logically perform better than the Pediatric Index of Mortality (PIM) models in ICUs with high mortality rates (2). However, the studies comparing the two scores in settings with high mortality show mixed results (3-5). For example, a study from India reported good 


\section{Apêndice C - Resposta à Carta do Editor}

Letters to the Editor

7. Lawrence SE, Cummings EA, Gaboury I, et al: Population-based study of incidence and risk factors for cerebral edema in pediatric

8. Edge JA, Hawkins MM, Winter DL, et al: The risk and outcome of cerebral oedema developing during diabetic ketoacidosis. Arch Dis

DOI: $10.1097 /$ PCC. 0000000000000061

\section{The author replies:}

Tn response to the article by DeCourcey et al (1) and the editorial (2), Tasker and Burns (3) present an argument to 1 temper the impression that the use of hypertonic saline is associated with harm in pediatric diabetic ketoacidosis (DKA). Their main argument surrounds the significant decrease in DKA-related mortality and the significance of the mortality effect with hypertonic saline only when age and race were excluded from the model. The facts surrounding the age and race effects of DKA-related outcomes have, as Tasker and Burns (3) comment, previously been documented. However, in the present study where age and race were missing in less than $10 \%$ of cases, these two potential confounders were not significant in the multivariable analysis and hence were excluded from the final model, where hypertonic saline was associated with mortality. This approach of removing variables from final models when they are not significant is not uncommon and considered to be a valid methodological process. While Tasker and Burns (3) make the good point that an observed $83 \%$ decrease in mortality coincident with the use of hypertonic saline should not translate to a reversal to the use of mannitol per se, DeCourcey et al (1) appropriately and cautiously conclude in the article, "... equipoise regarding choice of therapy for treatment of cerebral edema in diabetic ketoacidosis should be maintained until a more definitive study is performed to guide therapy of this potentially lethal complication," reflecting the intent of the message by Tasker and Burns (3). It appears that we are all in agreement that future work is needed to elucidate not only the DKA condition but also the mechanisms of the treatment paradigms, which when employed without evidence may cause harm.

Dr. Vavilala received support for article research from the National Institutes of Health.

Monica S. Vavilala, MD, Department of Anesthesiology and Pain Medicine, Harborview Medical Center, University of Washington, Seattle, WA

\section{REFERENCES}

Decourcey DD, Steil GM, Wypij D, et al: Increasing use of hypertonic saline over mannitol in the treatment of symptomatic cerebral edema in pediatnc diabetic ketoacidosis: An 11-year retrospective analysis

2. Vavilala MS: Treating cerebral edema in diabetic ketoacidosis: Caveats in extrapolating from traumatic brain injury. Pediatr Crit Care

3. Tasker RC, Burns J: Hypertonic Saline Therapy for Cerebral Edema in Diabetic Ketoacidosis: No Change Yet, Please. Pediatr Crit Care

DOI: 10.1097/PCC. 0000000000000062
The Use and Evaluation of Pediatric Index of Mortality and Pediatric Risk of Mortality in Pediatric Intensive Care

To the Editor:

The mortality prediction models Pediatric Index of Mortality (PIM) and Pediatric Risk of Mortality (PRISM) were developed to help PICUs to assess how well they look after critically ill children. Unfortunately, they are widely misunderstood. For example, in a recent issue of Pediatric Critical Care Medicine, Zanatta et al (1) report a tiny study of PIM2 in 395 critically ill children with only about 59 deaths (and no information about how the accuracy of the data was assessed). They suggest that PIM2 had poor discrimination because the receiver-operating characteristic (ROC) plot had an area of only 0.65 ; however, the $95 \% \mathrm{Cl}$ for the ROC area was $0.57-0.72$ and it overlapped the $95 \%$ CI of $0.69-0.83$ for the ROC area for PRISM in another study where they concluded that PRISM had acceptable discrimination. Given that the $95 \% \mathrm{CI}$ for the ROC areas for PIM2 and PRISM overlapped, it is likely that there was no statistically significant difference in the discrimination of the two scores.

Both Zanatta et al (1) and Sankar and Sankar (2) compare various versions of PIM and PRISM on the basis of how well they calibrated as judged by the Hosmer-Lemeshow test (and how well they discriminated as judged by the ROC area). It is important to understand that in most situations mortality models, such as PIM and PRISM, should not be assessed on the basis of the Hosmer-Lemeshow $p$ value. I explained the use of PIM and PRISM in an editorial published in 2002 (3), where I wrote that, "When you analyse your data, the Hosmer-Lemeshow test will almost always show a poor fit of the model-unless the numbers of observed and predicted survivors and nonsurvivors are similar at all deciles of risk (i.e., on all ten lines of the table). A significant HosmerLemeshow test does not demonstrate that PRISM or PIM is inappropriate for your unit-it is far more likely to occur because the standard of care in your unit is better or worse than in the units that derived the score (at the time it was derived). If your SMR is significantly different from 1.00 (the $95 \%$ confidence limits do not include 1.00 ), you should expect the Hosmer-Lemeshow $p$ value to be less than 0.05. Far too often, when the Hosmer-Lemeshow $p$ value is less than 0.05 , investigators conclude (incorrectly) that this means that the mortality prediction model that they have used is not valid in their intensive care unit."

Intensivists should stop collecting small amounts of data from a single ICU and then "validating" PIM or PRISM. PIM and PRISM have already been rigorously validated; we know they are accurate if used in the correct way. They are probably appropriate for your unit if the ROCarea is greater than 0.7 ; if it is less than 0.7 , poor quality data are by far the most likely explanation. You need at least 100 deaths in your sample before you use the standardized mortality rate (SMR) to decide whether your ICU performs better or worse than the units that derived the model (at the time it was derived). If your SMR differs from 1.00 , you should expect the Hosmer-Lemeshow test to be significant, and $p<0.05$ does not mean that PIM or PRISM is inappropriate for your unit. Far too 
often people use their unit's data to "evaluate" the performance of PIM or PRISM rather than using PIM or PRISM to evaluate their unit's performance. Because PIM and PRISM predict fewer deaths in later versions, you make your unit look better than it really is if you use an out-of-date version of PIM or PRISM.

When choosing whether to use PIM or PRISM, it is important to note that PIM uses data available at the time of admission, whereas PRISM uses the worst value of physiological variables collected ower the first 12 or 24 hours. First, as Sankar and Sankar (2) point out, it is much easier to collect the data for admission scores like PIM, and accurate data collection is crucially important. Second, scores like PRISM that use the worst value of physiological variables in the first 12-24 hours are affected by the quality of care provided - the very thing that we are trying to assess; patients mismanaged in a bad unit will have higher PRISM scores than similar patients managed in a good unit, and the bad unit's high mortality will be incorrectly attributed to its having sicker patients (4). Third, worst in 12- to 24-hour scores such as PRISM give a spurious impression of accuracy (4): many deaths occur during the first 12-24 hours in intensive care, and during this time, PRISM is diagnosing death rather than predicting it (it is not difficult to detect that something is wrong with a dead patient). Fourth, worst in 12-to 24-hour scores are strongly influenced by the way the data are collected, being about $25 \%$ higher with continuous computer monitoring than with manual recording (4).

I strongly suggest that intensivists carefully read my description of the use of PIM and PRISM before using these tools (3) and especially before publishing their data.

The author has disclosed that he does not have any potential conflicts of interest.

Frank Shann, MD, FRACP, FCICM, Intensive Care Unit, Royal Children's Hospital, University of Melboume,

Melboume, Victoria, Australia

\section{REFERENCES}

1. Zanatta Gde A, Carvalho WB, Delgado AF: Selecting the Best Mortaity Risk Scoring Systems in a PICU: A Difficult Decision. Pediatr Crit Care Med 2013; 14:734

2. Sankar J, Sankar MJ: Selecting the best mortality risk scoring systems in a PICU: A difficut decision-The authors reply. Pediats Chit Care Med 2013; 14:734-735

3. Shann F: Are we doing a good job: PRISM, PIM and all that. Intensive 4. Shann F: Mortality prediction model is preferable to APACHE. BMJ
$2000 ; 320: 614$

DOI: $10.1097 /$ PCC. 0000000000000070

\section{The authors reply:}

1 though the concept of quality in healthcare is not something new, its applicability aims at improving the quality of the services as well as patients safety during treatment, especially in intensive care due to the significant impact on prognosis and costs (1). One way to assess the quality of the service provided in PICU is the utilization of mortality scoring systems, especially in developing countries where resources are scarce and these scores may contribute to the treatment. Two scores

Pediatric Critical Care Medicine that have absolutely international validation are the Pediatric Risk of Mortality and Pediatric Index of Mortality.

We agree with Shann $(2,3)$ that the performance of score in a specific unit should be assessed meticulously to determine if the quality care is appropriate and if the score in question is suitable. Classically, this evaluation is performed by standardized mortality rate that evaluates the unit and compares the observed and expected mortality; discrimination, the ability of a test to differentiate patients who meet death, which was assessed by measuring the area under the receiver operator characteristic-it is considered that an area from 0.70 to 0.79 is acceptable, from 0.80 to $0.89 \mathrm{good}$, and above 0.90 excellent (4); and calibration across risk of death, which was assessed by calculating the expected and observed number of survivors and deaths in deciles of risk. The Hosmer-Lemeshow goodness-of-fit chi-square statistic was calculated as $\Sigma(O-E 2 / E)$, where $O$ is observed and $E$ is expected number of survivors and deaths in each decile of risk. For this test, $p$ value greater than 0.05 is considered significant, so the higher the value of $p$, the better the fit of the model (5).

The choice of using a score may depend on the characteristics of the individual unit such as waiting time in the emergency department, type of disease (e.g., oncologic patients), chronic condition, and transportation to the PICU. Unfortunately, in developing countries, there is a great difficulty in getting beds in PICU and transport is not satisfactory in some cases, which could compromise data collection in the first hour of admission. Furthermore, in our tertiary PICU, $86 \%$ of patients had underlying disease, and the median length of stay of patients who died was higher compared with survivors ( $10 \mathrm{~d}$ vs $5 \mathrm{~d}$, respectively) (de Araujo Costa Zanatta et al, unpublished data, 2008). Ideally, multicenter studies have greater statistical significance, as published by Slater and Shann (6). However, larger studies in homogeneous populations, especially in developing countries, are difficult to be performed. Despite its limitations, studies involving smaller populations should not be disregarded if critically analyzed (7-10).

In conclusion, all validated scores are useful but their application depending on the characteristics of involved population and reliable assessment requires rigorous specific training and strict adherence to guidelines. Even out-of-date version of scores may apply if well known by the staff of PICU, particularly in countries where resources are scarce but they should be critically analyzed to evaluate the impact on improving the quality of care.

We declare that this article is in accordance with all ethical aspects of our country.

The authors have disclosed that they do not have any potential conflicts of interest.

Graziela de Araujo Costa Zanatta, MD, Artur

Figueiredo Delgado, MD, PhD, Pediatric Critical Care

Unit, Instituto da Criança Hospital das Clinicas da Faculdade

de Medicina da Universidade de Sao Paulo, Sao Paulo, Brazil

\section{REFERENCES}

1. Marcin JP, Pollack MM: Review of the acuity scoring systems for the pediatric intensive care unit and their use in quality improvement. $J$
Intensive Care Med 2007; 22:131-140 
discrimination with all the three scores (PRISM, PIM, and PIM-2) but calibration was good with only PRISM and PIM2. The standardized mortality ratio (SMR) was more than with all the three models. The mortality rate was high at $35 \%$ in this study (3). In another study from India, with mortality rate of $24.7 \%$, the authors observed the PRISM model to calibrate well as compared to PIM, although the discrimination was good and comparable between the models (4). In contrast to these studies, in a study from Pakistan of 131 patients, both the PRISM and PIM calibrated well, but discrimination was good for PIM-2 only while it was only acceptable for PRISM (5). The SMR again was more than 1 for both models in their study with a mortality rate of $28 \%$. In our study, we found acceptable discrimination and good calibration of the models in terms of both goodness-of-fit test and SMR (6). Thus from the available literature, it appears that both PIM-2 and PRISM perform reasonably well in settings with high mortality rates.

Our choice of the risk prediction model is more to do with the feasibility-it is practically not possible with the limited manpower to collect the large number of variables required for PRISM score. It may be feasible to collect these many variables for a limited period, say, during a research study with additional staff but it is not possible to sustain the quality of data collection on a regular basis in our setup. Therefore, we prefer using the PIM models. Finally, as pointed out by the authors the choice of using one model over another should be based on the data from the unit, the country/geographi$\mathrm{cal} /$ socioeconomic region of origin, and the feasibility of data collection of the variables required to calculate the score.

Dr. Thuma Sankar is employed by PGIMER, Dr RML Hospital and IMCR. Dr. Jeeva Sankar is employed by All India Institute of Medical Sciences, New Delhi and IMCR.

Jhuma Sankar, MD, Department of Pediatrics, PGIMER,

Dr. RML Hospital, New Delhi, India; M. Jeeva Sankar, MD, DM, All India Institute of Medical Sciences, New Delhi, India

\section{REFERENCES}

1. Zanatta GAC, Carva ho WB, Delgado AF: Selecting the Best Mortality Risk Scoring Systems in a PICU: A Difficult Decision. Pediatr Con Care Med 2013; 14:734

2. Pollack MM: Clinical scoring systems in pediatric intensive care. In Pediatric Critical Care. Fuhman BP, Zimmerman JJ (Eds). St. Louis, Mosby Year Book, 1992, pp 153-162

3. Thukral A, Lodha R, Irshad M, et al: Performance of Pediatric Risk of Mortaity (PRISM), Pediatric Index of Mortality (PIM), and PIM2 in a pediatric intensive care unit in a developing country. Pediatr Crit Care Med 2006; 7:356-361

4. Taori RN, Lahiri KR, Tullu MS: Performance of PRISM (Pediatric Risk of Mortality) score and PIM (Pediatric Index of Mortality) score in tertiary care pediatric ICU. Indian J Pediatr 2010; 77:267-271

5. Qureshi AU, Ali AS, Ahmad TM: Comparison of three prognostic under Pakistani circurrstances. I Ayub Med Coll Abbottabad 2007; 19:49-53

6. Sankar J, Chandel A, Dubey NK, et al: Do interventions in an ICU affect the predictive ability of pediatric index of mortality and pediatric
index of mortality-2 scores in a tertiary care hospital? Pediatr Crit Care Med 2013; 14:e70-e76

DOI: 10.1097/PCC.0b013e31829b1beg

Pediatric Critical Care Medicine
Duration of Gastrointestinal Colonization by Extended-Spectrum $\beta$-Lactamase-Producing Enterobacteriaceae Acquired by Infants in the Neonatal ICU

\section{To the Editor:}

W

$\mathrm{e}$ read with great interest the article by Strenger et al (1) on fecal carriage and intrafamilial spread of extended-spectrum $\beta$-lactamase (ESBL)-producing Enterobacteriaceae following colonization at the neonatal ICU (NICU). We agree that only a few data are available on the issue of duration of ESBL gastrointestinal colonization among children. Furthermore, we think that there is substantial parental anxiety concerning these multidrug-resistant strains colonizing young infants discharged from the NICU. We feel data are urgently needed in order to answer appropriate and common questions regarding the duration of colonization and the risk of infection (i.e., urinary tract infection) in carriers of these isolates.

Due to previous detection of ESBL+ isolates in our NICU at the Western Galilee Hospital in Israel, we carry out a weekly screen of the entire NICU population for rectal carriage of ESBL-producing Enterobacteriaceae in order to detect early colonization and use appropriate isolation (2). Our NICU is a 26-bed tertiary level unit with approximately 550 annual admissions. Use of pulsed-field gel electrophoresis demonstrated a major clone of ESBL+ Klebsiella pneumoniae. In orde to better define the duration of colonization and the risk factors for infection in carriers of ESBL+ strains, we conducted a retrospective cohort study of infants discharged from the NICU carrying ESBL+ isolates between the years 2007 and 2011. Rectal swabs were taken repeatedly from participants in 2011-2012 and demographic and clinical data collected. Isolates were compared by species and antimicrobial susceptibility. Identification of ESBL+ strains was performed according to the Clinical and Laboratory Standards Institute guidelines (3). The study was approved by the Institutional Review Board of Western Galilee Hospital and Israeli Ministry of Health.

Of 210 children acquiring ESBL colonization in the NICU, $65(31 \%)$ infants $1-51$ months old (median 25 mo) participated with at least one rectal swab; $63 \%$ had two or more swabs taken. The infants' mean gestational age, birth weight, and duration of stay in the NICU were 31 weeks, $1620 \mathrm{~g}$, and 36 days, respectively. The participating infants were colonized with $K$. pneumoniae $(62 / 65,95 \%)$ and Escherichia coli $(3 / 65$, $5 \%$ ). Mean time to acquisition of ESBL+ strain was 16 days. Rectal colonization was observed to the age of 6 months. Infants older than 6 months were not colonized. Although almost half of the infants $(31 / 65,48 \%)$ were readmitted, none were infected with ESBL+ strains.

Compared with the study by Strenger et al, we demonstrated a shorter duration of colonization with $K$. pneumoniae, the bacterium most of our infants had carried. The difference in duration might be explained by several factors, including difference in the strains, classes of ESBLs, antibiotic pressure 